\title{
Cytokine-modified VSV is attenuated for neural pathology, but is both highly immunogenic and oncolytic
}

This article was published in the following Dove Press journal:

International Journal of Interferon, Cytokine and Mediator Research

3 December 2009

Number of times this article has been viewed

\author{
James Miller' \\ Sarah M Bidula ${ }^{1,2}$ \\ Troels M Jensen ${ }^{1,3}$ \\ Carol Shoshkes Reiss ${ }^{1,4}$ \\ 'Department of Biology, New York \\ University, New York, NY, USA; \\ ${ }^{2}$ Present address: University of \\ Pittsburgh School of Medicine, \\ Pittsburgh, PA, USA; ${ }^{3}$ Present address: \\ New York School of Medicine, \\ New York, NY, USA; ${ }^{4}$ Center for \\ Neural Science, NYU Cancer Institute \\ and Microbiology Department, School \\ of Medicine, New York University, \\ New York, NY, USA
}

\begin{abstract}
Vesicular stomatitis virus (VSV), an enveloped, nonsegmented, negative-stranded RNA virus, is being tested by several laboratories as an antitumor agent. Unfortunately, viral infection of the central nervous system (CNS) has been observed by many groups following administration to tumor-bearing animals. In rodents, VSV encephalitis is characterized by weight-loss, paralysis, and high mortality. In order to provide protection from VSV infection of the CNS after therapeutic administration, we have attenuated VSV by the introduction of the gene encoding the proinflammatory cytokine interleukin (IL)-23, and designated the new virus VSV23. We hypothesize that while VSV23 is replicating within tumors, resulting in tumor destruction, the expression of IL-23 will enhance host antitumor and antiviral immune responses. In the event that the virus escapes from the tumor, the host's immune system will be activated and the virus will be rapidly cleared from healthy tissue. Experimental VSV23 infection of the CNS is characterized by decreased viral replication, morbidity, and mortality. VSV23 is capable of stimulating the enhanced production of nitric oxide in the CNS, which is critical for elimination of VSV from infected neurons. Intraperitoneal administration of VSV23 stimulates both nonspecific natural killer cell, virus-specific cytolytic T lymphocyte and memory virus-specific proliferative T cell responses against wild-type VSV in splenocytes. Furthermore, VSV23 is able to replicate in, and induce apoptosis of tumor cells in vitro. These data indicate that VSV23 is immunogenic, attenuated and suitable for testing as an efficacious and safe oncolytic agent.
\end{abstract}

Keywords: IL-23, oncolytic, tumor, VSV

\section{Introduction}

Vesicular stomatitis virus (VSV), a prototypical member of the genus Vesiculovirus, is a naturally occurring virus which is transmitted by sand flies to livestock and causes the eponymous small oral rashes. VSV infections in humans tend to be asymptomatic and generally limited to researchers and livestock handlers. Therefore, most humans are seronegative. ${ }^{1,2} \mathrm{VSV}$ is extremely sensitive to antiviral host cell interferon (IFN) responses. ${ }^{3-5}$ IFNs induced by VSV infection may help eliminate the virus and protect otherwise uninfected tissues, however blocking of host nuclear export by the VSV $\mathrm{M}$ protein is associated with viral evasion of IFN-induced cellular defenses. ${ }^{6-8} \mathrm{VSV}$ rapidly replicates and induces apoptosis in cells that have compromised interferon pathways, a common characteristic of many tumor cell lines. ${ }^{9-15}$ These traits make VSV an attractive agent for utilization as an oncolytic agent.

Inoculation of immunocompetent mice with high doses of VSV by the intramuscular, subcutaneous, or intraperitoneal (IP) routes generally leads to limited viral replication and no apparent disease. ${ }^{16-18}$ Intravenous inoculation of immunocompetent
Correspondence: Carol Shoshkes Reiss Department of Biology, New York University, I00 Washington Sq East, Silver Center room 1009, New York, NY, 10003-6688, USA

$\mathrm{Tel}+\mathrm{I} 2129988269$

Fax +I 2129954015

Email carol.reiss@nyu.edu
International Journal of Interferon, Cytokine and Mediator Research 2009:। 15-32

(c) 2009 Miller et al, publisher and licensee Dove Medical Press Ltd. This is an Open Access article which permits unrestricted noncommercial use, provided the original work is properly cited.
Dovepress 
mice with high doses of VSV can lead to very limited viral replication in the periphery, but can cause central nervous system (CNS) pathology if the virus gains access to the brain despite the induction of antibody responses. ${ }^{17,19,20}$ Immunocompromising the IFN signaling cascade or $\mathrm{T}$ cell deficiency leads to death following host infection. ${ }^{18,21-23}$ Studies have shown that if VSV infection of tumors reaches the host's CNS, viral encephalitis will result. ${ }^{10,24}$ Infection via intranasal (IN) administration results in severe pathology characterized by weight loss, hind-limb paralysis, and death. ${ }^{16,25,26}$ Immunocompetent mice develop high morbidity and mortality following IN infection at viral doses as low as 200 plaque-forming units (PFU), succumbing to infection between 6-11 days postinfection (PI). A recent study in nonhuman primates demonstrated significant neuropathology following intrathalamic inoculation. ${ }^{27}$ The neurotropism and neuropathology of VSV necessitates the development of an attenuated virus if VSV is to be used as a therapeutic.

During VSV infection of the CNS, neutrophils, natural killer (NK) cells, macrophages, and $\mathrm{T}$ cells are recruited to attack the virus at the site of infection. ${ }^{18,26,28-30}$ Plasmacytoid dendritic cells (pDC) in the lymph nodes and spleen respond to VSV infection through TLR $7 .^{31,32}$ Within 36 hours of infection, neutrophils are recruited from circulation; ${ }^{26,29}$ NK cells are detected at day three and onward in the brains of VSV infected hosts. ${ }^{26,29,33}$ Neutrophils play an early role in control of the rate of infection, as they produce nitric oxide (NO), $\mathrm{OONO}^{-}$, lipid mediators, as well as pro-inflammatory chemokines and cytokines, critical components of immunity in controlling early infections of the CNS. ${ }^{28}$

VSV proteins, processed by antigen-presenting cells, result in the induction of the adaptive immune response: $\mathrm{CD}^{+}$and $\mathrm{CD}^{+} \mathrm{T}$ cells as well as anti-VSV antibodies. ${ }^{34-38}$ The essential role of MHC II-restricted viral glycoprotein CD4 effector cells in recovery from viral encephalitis was shown in the BALB/cH-2 ${ }^{\mathrm{dm} 2}$ mouse strain. ${ }^{35}$ Neutralizing antibodies are directed against the glycoprotein with $\operatorname{IgM}$ produced first and IgG second. ${ }^{20,39}$

Interleukin (IL)-23 is a heterodimeric member of the IL-12 family of cytokines composed of a p40 subunit shared with IL-12 and a unique p19 subunit. A heterodimeric receptor IL-23R includes a unique chain and the IL-12R $\beta 1$ subunit. ${ }^{40}$ IL-23R is expressed on the surface of immune cells including T cells, NK cells, macrophages, and dendritic cells. Binding of IL-23 to IL-23R results in signaling through the Jak, Tyk, signal transducers and activators of transcription (STAT) pathways and the transcription factor RoR $\gamma \mathrm{T} .{ }^{41,42} \mathrm{IL}-23$ is produced by macrophages and dendritic cells. ${ }^{43}$ IL-23 also plays a role in the differentiation of proinflammatory $\mathrm{T}$ cells secreting IL-17. ${ }^{44}$ The IL-23/IL-17 cascade has been associated with several inflammatory illnesses including rheumatoid arthritis, psoriasis, and experimental allergic encephalomyelitis (EAE). ${ }^{45-48}$

Antimetastatic and antitumor properties have been associated with IL-23 and IL-12, however the therapeutic use of IL-12 in cancer treatment has been compromised by side-effects associated with the induction of IFN- $\gamma{ }^{49-54}$ The antitumor effects associated with IL-23 are attributed to production of tumor necrosis factor- $\alpha$ (TNF- $\alpha$ ) (not IFN- $\gamma$ ), and result in enhanced effectiveness of $\mathrm{CD} 8^{+} \mathrm{T}$ cells. ${ }^{55}$ Experiments indicated that depletion of NK cells had no affect on the antitumor activity of IL-23 as determined by tumor growth rate, however $\mathrm{CD}^{+} \mathrm{T}$ cell depletion significantly compromised the ability of naive mice to reject implanted tumors and limit tumor growth rates. ${ }^{56}$ Experiments conducted with IL-23-transduced CT26 cells and B16F1 tumor cells have shown increased antitumor memory $\mathrm{T}$ cell responses and decreased lung metastases in vivo. ${ }^{52}$ Experiments conducted with the murine mammary cancer cell line MA891, have shown that expression of IL-23 through retrovirus transduction resulted in increased antitumor CTL effectors. $^{57}$

Based on IL-23's proinflammatory activity in the CNS, we hypothesized that a recombinant VSV which expressed IL-23 would be attenuated in the CNS while still being fully immunogenic in the periphery. Additionally, this recombinant virus would maintain (and possibly enhance) its oncolytic capacity. To test this hypothesis we have generated a recombinant VSV that expresses a single chain IL-23 designated VSV23. Assays of innate and adaptive immune responses following parenteral challenge were performed to determine the immunogenicity of the virus. VSV23 has also been tested for attenuation in vitro and in vivo in the in model of VSV encephalitis. Finally the ability of VSV23 to infect and kill a mammary derived tumor cell line in vitro has been determined.

\section{Materials and methods} Plasmid production

To produce a recombinant VSV that expresses IL-23, single-chain IL-23 (scIL23) comprised of the p40 and p19 subunits joined with a flexible linker $\left[\left(\mathrm{Gly}_{4} \mathrm{Ser}\right)_{3}\right]$ was amplified by PCR from plasmid pCEP4-scIL23Ig, a generous gift from Dr Maria Laura Belladonna (University of Perugia, Italy). ${ }^{58}$ This reaction removed an Ig binding region from 
the 3' end and introduced XhoI and SpeI restriction sites at the $5^{\prime}$ and $3^{\prime}$ ends respectively, as well as a stop codon at the $3^{\prime}$ end. The forward primer sequence was 5'-TAGTCCTCGAGATGTGTCCTCAGAAGCTAACCATCT-3' and the reverse primer was 5'-TATGAACTAGTCTAAGCTGTTGGCACTAAGGGCT-3'. The amplified region was cloned into the VSV expression vector ( $\mathrm{pXN}$ 2) (the generous gift of Jack Rose, Yale University School of Medicine, New Haven, CT) and the resultant plasmid was designated pXN2-scIL23. ${ }^{59}$

To generate a control virus containing the IL-23 coding sequence, scIL23 was amplified from pCEP4-scIL23Ig, restriction digested with $\mathrm{KpnI}$ and $\mathrm{XbaI}$, then ligated with the intermediate vector pSP73. Three stop codons were introduced into the p40 subunit using the Quikchange SiteDirected Mutagenesis Kit (Stratagene, La Jolla, CA) per manufacturer's directions. The mutagenesis forward primer was 5'-ACTCCGGACGGTTCACGTGATGATGACTGGTGCAAAGAAACATGG-3' and the reverse primer was 5'-CCATGTTTCTTTGCACCAGTCATCATCACGTGAACCGTCCGGAGT-3'. XL1-Blue cells (Strategene) were transformed with the mutagenesis reaction polymerase chain reaction (PCR) product and plated on LB-Amp plates. Plasmids isolated from colonies and correct mutations were identified by sequencing at the New York University (NYU) Sequencing Core. Positive sequences were then subjected to PCR and subsequent cloning to the pXN2 plasmid as described above. The resultant plasmid was designated pXN2-scIL23ST.

\section{Cell lines}

BHK-21 baby hamster kidney cells, JC murine mammary gland adenocarcinoma-derived cells, L929 murine adipocytes and NB41A3 murine neuroblastoma cells were all purchased from the American Type Culture Collection (Manassas, VA). BHK-21 cells were grown in minimum essential media (Mediatech, Manassas, VA) with 1\% nonessential amino acids, $1 \%$ penicillin-streptomycin (pen-strep) and 10\% fetal bovine serum (FBS), JC cells grown in RPMI1640 (Mediatech) with 1\% pen-strep and 10\% FBS, L929 cells grown Dulbecco's modified Eagles' medium (Mediatech) with $1 \%$ pen-strep, $1 \%$ HEPES buffer, $1 \%$ L-glutamine and $10 \%$ fetal bovine serum (FBS), NB41A3 grown in F-12K media (Mediatech) with $2.5 \mathrm{FBS}$ and $15 \%$ horse serum.

\section{Recombinant VSV rescue}

Recombinant VSVs (rVSVs) were rescued in BHK-21 cells using the previously described reverse genetics method. ${ }^{59}$ Briefly, cells were infected with vaccinia virus expressing the
T7 RNA polymerase, then transfected with pXN2-scIL23, pXN2-scIL23ST, or pXN2 to produce VSV23, VSVST, and VSVXN2 respectively. In addition, plasmids encoding N, P, and $\mathrm{L}$ proteins were co-transfected using LipofectAMINE 2000 (Invitrogen, Carlsbad, CA). Vaccinia virus was removed by filtration through a $0.20 \mu \mathrm{m}$ filter after 48 hours of incubation. Filtrate was added to fresh BHK-21 cells. Subsequently, individual clones were plaque purified and used for production of viral stocks. Titers of rVSV were determined by plaque assay on L929 cells.

\section{One-step growth curve}

L929 cells were grown to $90 \%$ confluence in 24-well plates and infected with VSV23, VSVST, VSVXN2, or VSVwt (Indiana serotype, San Juan strain, originally obtained from Alice S. Huang, then at The Childrens' Hospital, Boston, MA) at a multiplicity of infection (MOI) $=1$ for 30 minutes at room temperature (RT). Wells were washed with HBSS to remove unadsorbed virus and media was added to each well. Aliquots of media were removed at 1.5, 3, 6, 12, and 24 hours and stored at $-80^{\circ} \mathrm{C}$. Viral titers were determined by plaque assay on L929 cells. All samples were assayed in triplicate and the experiment repeated twice.

\section{ELISA for virally produced IL-23}

HK-21 cells were infected with VSV23, VSVST, or VSVXN2 at MOI $=0.1$ and incubated overnight at $37^{\circ} \mathrm{C}$ and $5 \% \mathrm{CO}_{2}$. Uninfected BHK-21 cells were used as a negative control. Supernatants were harvested and subjected to ELISA analysis specific for the p40 subunit of IL-23 using the mouse IL-12/IL-23 Total p40 ELISA kit (eBioscience, San Diego, CA).

\section{Animals}

All procedures involving animals were approved by and performed according to the guidelines of The University Animal Welfare Committee of New York University. Six-week old male BALB/cAnNTac (BALB/c) mice were purchased from Taconic Farms, Inc. (Germantown, NY), housed under standard conditions and fed ad libitum. Mice were housed at NYU for one week prior to initiation of experiments.

\section{Induction of IFN- $\gamma$}

Spleens were aseptically harvested from eight-week old male $\mathrm{BALB} / \mathrm{c}$ mice and teased into single cell suspensions. CD4 ${ }^{+}$ cells were isolated using the Dynal ${ }^{\circledR}$ Mouse CD4 Negative Isolation Kit (Oslo, Norway) and added to 6-well plates from Fisher Scientific (Pittsburgh, PA) with DMEM supplemented 
with $10 \%$ heat inactivated FBS and $1 \%$ pen/strep. CD $4^{+}$cells were treated with ultraviolet-inactivated supernatants from BHK-21 cells containing 500 pg of VSV23 induced IL-23 (vIL-23). UV-inactivated supernatants containing $500 \mathrm{pg}$ of virally induced IL-12 (vIL-12) from BHK-21 cells infected with a rVSV expressing IL-12, [the generous gift of Dr Savio Woo (Mt Sinai School of Medicine, New York, NY)] were also tested. ${ }^{60} 500 \mathrm{pg}$ of recombinant IL-23 (rIL-23) or rIL-12 (R\&D Systems Minneapolis, MN) were used to treat cells as positive cytokine controls and supernatant from untreated/ uninfected BHK-21 cells was used as a negative control. Samples were incubated at $37{ }^{\circ} \mathrm{C}$ and $5 \% \mathrm{CO}_{2}$ for six hours and RNA was isolated with Trizol $^{\circledR}$ reagent (Invitrogen, San Diego, CA). RNA was subjected to reverse transcriptasePCR for detection IFN- $\gamma$ mRNA. The forward primer was 5'-GCTTTGCAGCTCTTCCTCAT-3' and the reverse primer was 5'-TGAGCTCATTGAATGCTTGG-3'. Beta actin was used as a housekeeping control for the reaction. The forward primer was 5'-AAGAGCTATGAGCTGCCTGA-3' and the reverse primer was 5'-TACGGATGTCAACGTCACAC-3'.

\section{NK assay}

Cohorts of $N=6$, six-week old male BALB/c mice were inoculated IP with $1 \times 10^{7}$ pfu of VSV23, VSVST, VSVXN2, VSVwt, or mock infected as a control. Three days later, spleens from individual mice were harvested, teased into a single cell suspension, and resuspended in MEM, 10\% FBS, 1\% Pen-Strep. $1 \times 10^{4}$ YAC-1 cells were plated in 96-well V-bottom plate wells in $100 \mu \mathrm{l}$ of MEM supplemented with $10 \% \mathrm{FBS}$ and 1\% Pen-Strep. Splenocytes were co-incubated with YAC-1 cells in triplicate at ratios of 200:1, 100:1, 50:1, 25:1, and 12.5:1, and 6.25:1 in a total volume of $100 \mu \mathrm{l}$. Plates were centrifuged at $200 \times \mathrm{g}$ for 5 minutes to improve contact between cells and incubated for four hours at $37{ }^{\circ} \mathrm{C}, 5 \% \mathrm{CO}_{2}$. The CytoTox $96^{\mathrm{TM}}$ nonradioactive cytotoxicity kit (Promega $\mathrm{C}$, Madison, WI) was used per manufacturer's instructions to determine NK mediated cytolytic activity. Results were read on a Biorad 550 series microplate reader (Hercules, CA) at $490 \mathrm{~nm}$. Results are representative of two replicate experiments.

\section{CTL assay}

Cohorts of $N=6$, six-week old male BALB/c mice were injected IP with $1 \times 10^{7}$ pfu of VSV23, VSVST, VSVXN2, or VSVwt, to produce responder cells. Mock-injected mice were used as a negative control and as a source of naive controls for effector cells. Twenty days after immunization, spleens from individual mice were harvested, teased into a single cell suspension, and resuspended in MEM, 10\% FBS,
1\% Pen-Strep. Stimulator cells were prepared by infecting naive splenocytes with VSV tsG41 at MOI $=5$ at the permissive temperature of $33{ }^{\circ} \mathrm{C}$ for one hour. ${ }^{37}$ Cells were washed in HBSS to remove unadsorbed virions. $5 \times 10^{6}$ responder cells were cultured with $1 \times 10^{6} \mathrm{VSV}$ tsG41 stimulator cells or with uninfected stimulator cells for five days in DMEM, $10 \%$ FBS, $1 \%$ Pen-Strep, 5 mM 2-mercaptoethanol, and 1\% L-glutamine at $37{ }^{\circ} \mathrm{C}, 5 \% \mathrm{CO}_{2}$. A20 cells (syngeneic $\mathrm{H}-2^{\mathrm{d}}$ MHC I and MHC II-expressing) were used as target cells. ${ }^{35,61}$ Target cells were either infected with VSVwt at multiplicity of infection $(\mathrm{MOI})=3$ or mock-infected and plated in 96 well V-bottom plates at $1 \times 10^{4}$ cells per well. Responder cells from individual mice of each treatment group were added to target cells in triplicate at effector to target ratios of 100:1, 50:1, $25: 1$, and 12:1. Plates were centrifuged for five minutes at $200 \times \mathrm{g}$ to improve cell contacts and incubated for four hours at $37^{\circ} \mathrm{C}, 5 \% \mathrm{CO}_{2}$. The CytoTox $96^{\mathrm{TM}}$ nonradioactive cytotoxicity kit (Promega) was used per manufacturer's instructions to determine $\mathrm{T}$ cell mediated cytolytic activity. Results were read on a Biorad 550 series microplate reader at $490 \mathrm{~nm}$. Results are representative of two replicate experiments.

\section{Proliferation assay}

Cohorts of $N=6$, six-week-old male BALB/c mice were inoculated IP with $1 \times 10^{7}$ pfu of VSV23, VSVST, VSVXN2, or VSVwt to produce responder cells. Mock-treated mice were used as a negative control. Twenty days later, spleens were harvested, teased into a single cell suspension, and resuspended in MEM supplemented with 10\% FBS and $1 \%$ Pen-Strep. Stimulator cells were prepared by treating naive spleen cells with five pfu of VSVtsG41 per cell at the permissive temperature of $33^{\circ} \mathrm{C}$ for 1 hour. Cells were washed in HBSS to remove unabsorbed virions. $1 \times 10^{5}$ responder cells from individual mice were seeded in a 96 -well plate, in triplicate, with either $1 \times 10^{5}$ of VSVtsG41 infected or uninfected stimulator cells and allowed to incubate for 3 days in MEM supplemented with 10\% FBS, $1 \%$ Pen-Strep, 2-mercaptoethanol, and L-glutamine at $37^{\circ} \mathrm{C}$, $5 \% \mathrm{CO}_{2}$. The Cell Proliferation ELISA, BrdU (colorimetric) kit (Roche Diagnostics, Indianapolis, IN) was utilized per manufacturer's instructions and the results read on a Biorad 550 series microplate reader at $490 \mathrm{~nm}$. Results are representative of two replicate experiments.

\section{Neutralization assay}

Cohorts of $N=10$, six-week old male BALB/c mice were infected in with $1 \times 10^{3}$ pfu of VSV23, VSVST, VSVXN2, or VSVwt. Uninfected animals were used as a control. 
Blood samples were collected from the ocular plexus 20 days PI from surviving individual animals and allowed to clot overnight at $4{ }^{\circ} \mathrm{C}$. Serum was diluted in PBS in serial five-fold steps. $1 \times 10^{3}$ pfu of VSVwt was added to each dilution and incubated at $37{ }^{\circ} \mathrm{C} 5 \% \mathrm{CO}_{2}$ for 1 hour. Plaque assays were performed in triplicate samples on L929 cells and neutralizing antibody titers were calculated. Results are representative of three replicate experiments.

\section{Viral titers and nitric oxide levels in CNS}

Cohorts of $N=6$, six week-old male BALB/c mice were infected IN with $1 \times 10^{3}$ pfu or $1 \times 10^{6}$ of VSV23, VSVST, or VSVXN2. Individuals were sacrificed on days 1, 3, 6, and 9 $\mathrm{PI}$ and brains were divided sagittally. One half was reserved for immunohistochemical staining. The other brain half was individually homogenized, and an aliquot was serially diluted, and assayed in triplicate by plaque assay on L929 cells for the presence of VSV. Geometric mean titers were calculated for each cohort. Homogenate samples for NO assays were pre-cleared of solid material by centrifugation. The Total Nitric Oxide Assay Kit (Pierce, Rockford, IL) was used as per manufacturer's instructions to convert nitrate to nitrite from individual samples. Equal volumes of experimental sample and Greiss reagent (1\% sulfanilamide, $0.1 \% \mathrm{~N}-$ 1-naphthylethylene-diamine, and 5\% $\mathrm{H}_{3} \mathrm{PO}_{4}$; Sigma-Aldrich, St. Louis, MO) were incubated in the dark at room temperature for 10 minutes and results were read on a Biorad 550 series microplate reader at $540 \mathrm{nM}$.

\section{Morbidity and mortality assay}

Cohorts of $N=10$, six-week old male BALB/c mice were infected in with $1 \times 10^{4}$ or $1 \times 10^{6}$ pfu of VSV23, VSVST, VSVXN2, or VSVwt and monitored daily for 15 days. Mice were weighed daily. Hind-limb paralysis or weight loss that exceeded $30 \%$ of starting weight were considered end points for the experiment. Mice were individually scored blind on a subjective six point scale (0-5): "0" for no symptoms, " 1 " for lack of grooming behavior, " 2 " for hunched and severely lethargic mice, " 3 " for hind-limb paralysis, " 4 " for full paralysis, and " 5 " for deceased. The experiment was single-blinded.

\section{In vitro infection of target JC cell}

JC cells were seeded in 96-well plates at a concentration of $4.5 \times 10^{4}$ and incubated overnight at $37^{\circ} \mathrm{C}, 5 \% \mathrm{CO}_{2}$. Six replicate wells were used for each treatment condition and time point. Cells were then infected at $\mathrm{MOI}=3.0$ with VSV23,
VSVST, VSVXN2, or VSVwt and incubated at $37{ }^{\circ} \mathrm{C} 5 \% \mathrm{CO}_{2}$ for $3,6,9,12,18$, or 24 hours. Mock infected cells were used as a negative control. The TACS MTT Cell Proliferation Assay (R\&D Systems Minneapolis, MN) was used per manufacturer's instructions to conduct the assay. Samples were read at $540 \mathrm{nM}$ on a Biorad 550 series microplate reader.

\section{Statistical analysis}

GraphPad Prism statistical software (GraphPad Software Inc., La Jolla CA) was used for ANOVA, Kruskal-Wallis, Student's $t$-test, and Kaplan-Meier statistical analyses.

\section{Results \\ Recombinant VSV construction and characterization}

In order to produce a rVSV that expresses IL-23, the cDNA of a single chain IL-23 (scIL-23) comprised of the p40 and p19 subunits joined by a flexible linker was cloned into the $\mathrm{pXN} 2$ plasmid (Figure 1A) to produce the pXN2-scIL23 plasmid (Figure 1B). IL-23 was chosen for its proinflammatory and intrinsic oncolytic properties. The reverse genetics method described by the Rose lab was used to produce VSV23. ${ }^{59}$ To control for attenuation of VSV resulting from alterations in genome size and particle morphology, two control viruses were produced utilizing the same reverse genetics approach. The first, VSVST, was generated by insertion of a mutagenized cDNA for IL-23 that contained three stop condons in the p40 subunit into pXN2 (Figure 1C). The second, VSVXN2, was rescued with an unaltered pXN2 plasmid.

If VSV23 were to have impaired replication kinetics, this would be adverse to the intended use for oncolysis. In order to determine if the kinetics of VSV23 infection were similar to VSVwt and controls, a one-step growth curve was conducted in L929 cells. At all time points, viral titers were comparable, indicating that genome alterations do not result in diminished infectivity or reduced replication capacity (Figure 2). Data are representative of three replicate experiments and expressed as means \pm standard deviation.

To determine if IL-23 were secreted by VSV23 infected cells, but not by cells infected with control viruses, we tested supernatants with an ELISA specific for the p40 subunit if IL-23. BHK-21 cells were infected at MOI $=0.1$ and incubated for 24 hours. Only supernatants from VSV23 infected cells contained detectable levels of IL-23 (Figure 3A). Stop codons inserted into the $\mathrm{p} 40$ subunit of IL-23 in the VSVST viral genome successfully prevented transcription, translation and secretion of IL-23, thus validating the use of this virus as a control. 

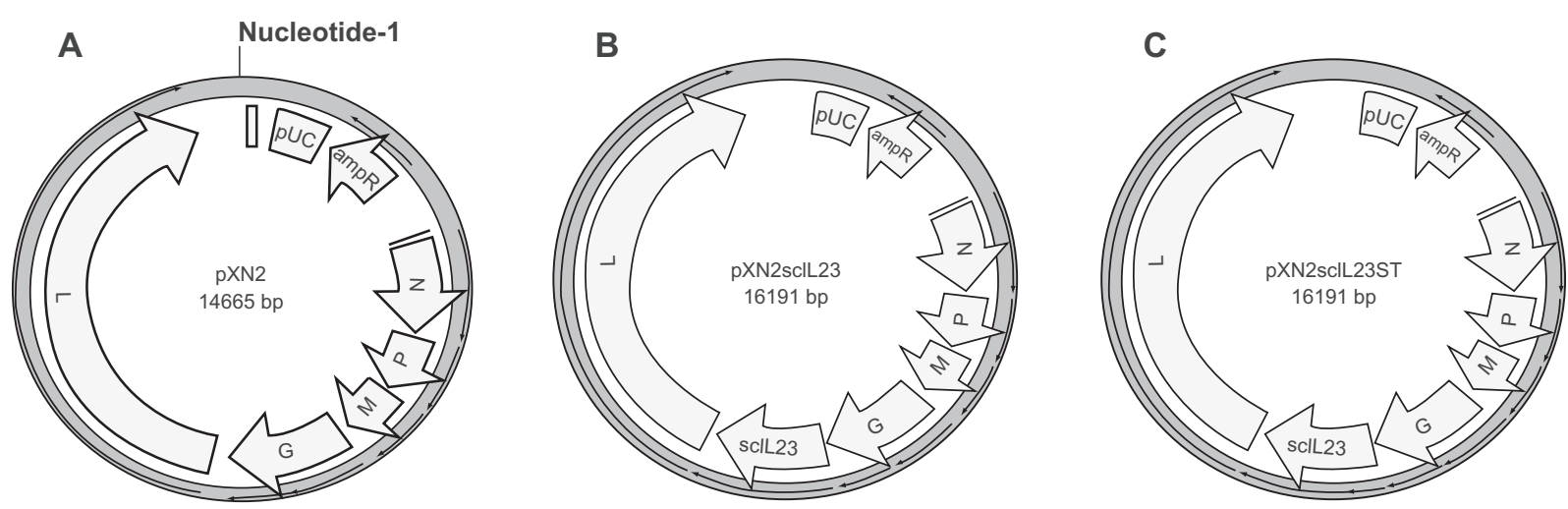

Figure I Virus production plasmids. A) VSVXN2. is a plasmid map of the $14.6 \mathrm{~kb}$ pXN2 plasmid that serves as the cloning vector in the recombinant VSV system and used for the rescue of VSVXN2. B) VSV23.A single chain IL23 was created by linking the coding regions for the $\mathrm{p} 40$ and p 19 subunit with a flexible linker and inserted in the $p X N 2$ expression vector at the Xhol/Nhel mcs. The resultant plasmid was designated pXN2sclL23 and used for the rescue of VSV23. C) VSVST. Point mutations were induced in the pXN2sclL23 plasmid to introduce 3 stop codons in the p40 subunit coding region. This plasmid was used in the rescue of VSVST. All three plasmids were subsequently co-transfected into BHK-2I cells with 3 helper plasmids individually coding N, P, and L.A previous infection of vaccinia virus provides the T7 polymerase for expression of the viral genes in the cytoplasm of the cells.

Abbreviation: MCS, multiple cloning sites.

Among concerns about the efficacy of VSV23, was the ability to produce an active cytokine. To determine the bioactivity of virally induced IL-23 (vIL-23), isolated CD4+ cells were treated with vIL-23 and probed for IFN- $\gamma$ mRNA. $\mathrm{CD} 4{ }^{+}$cells were isolated from spleens of male $\mathrm{BALB} / \mathrm{c}$ mice and incubated with supernatants from BHK-21 cells that had been infected for 24 hours with VSV23. Supernatants from BHK-21 cells that had been infected with a rVSV that expresses IL-12 were used as a positive control, along with commercially available IL-23 and IL-12. Mock infected cells and BHK-21 cells which were infected with VSVST or with VSVXN2 did not induce IFN- $\gamma$ mRNA (data not shown).

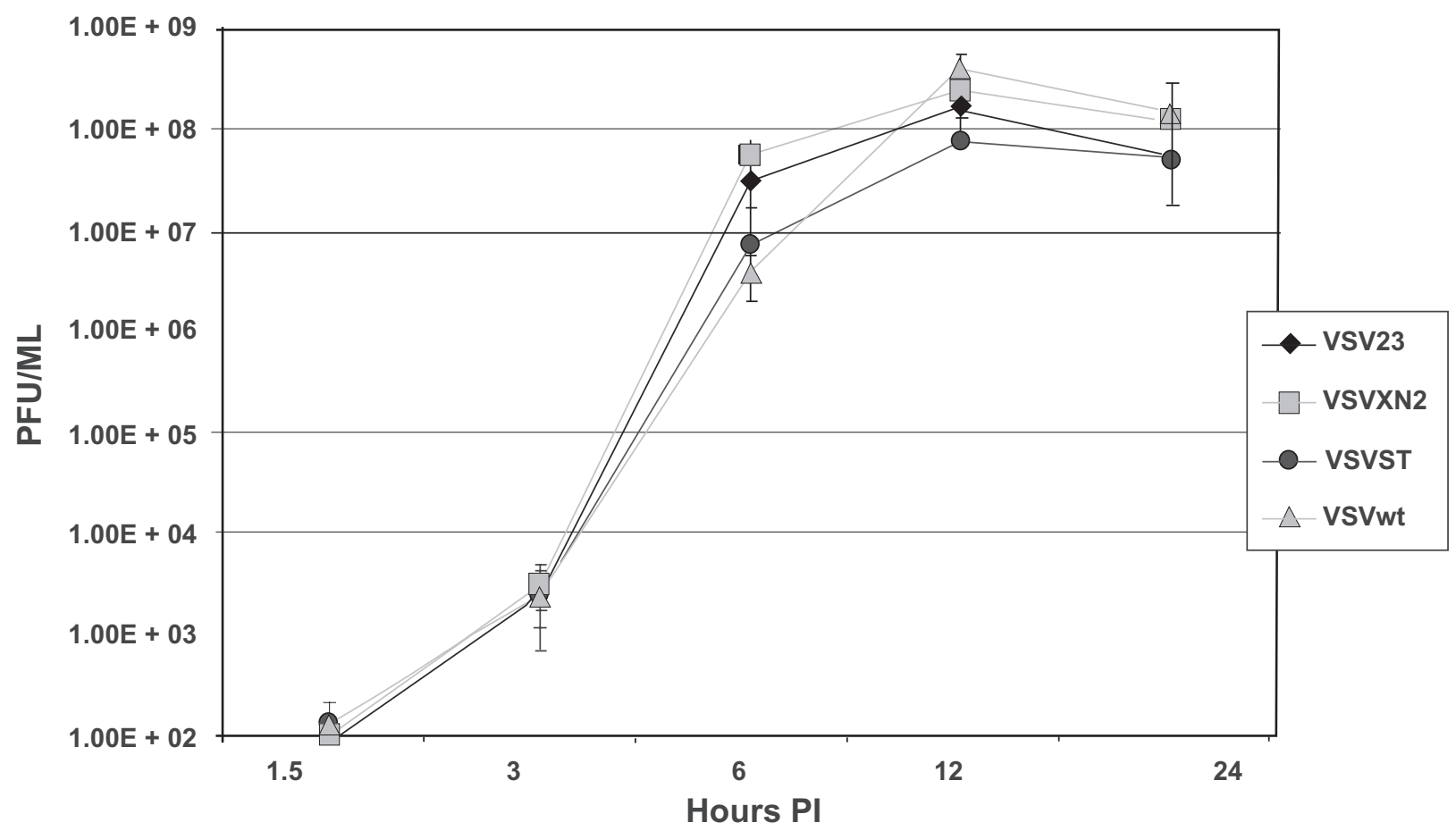

Figure 2 One-step growth curve: VSV23 (diamond), VSVST (circle), VSVXN2 (square), and VSVwt (triangle) were used to infect L929 cells at an MOI = I in triplicate. Media samples were removed at $1.5,3,6,12$, and 24 hours and stored at $-80^{\circ} \mathrm{C}$.Virally infected supernatants were serially diluted and transferred to fresh L 929 cells for plaques assay. Growth kinetics for all viruses are similar at all time points. Data presented are geometric means \pm standard deviation and are representative of three replicate experiments. Abbreviations: $\mathrm{PI}$, post infection, $\mathrm{MOI}$, multiplicity of infection; VSV, vesicular stomatitis virus. 
A

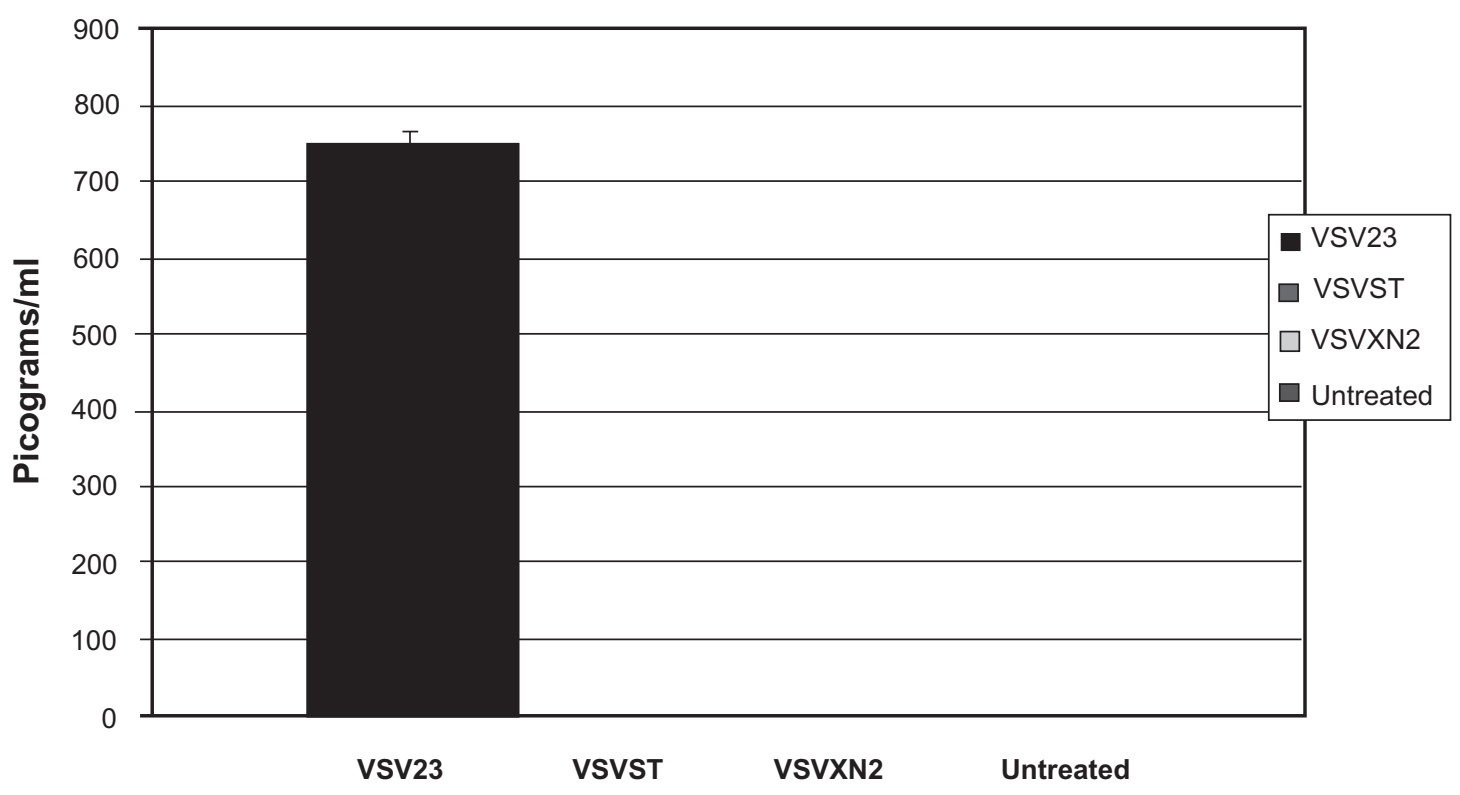

B

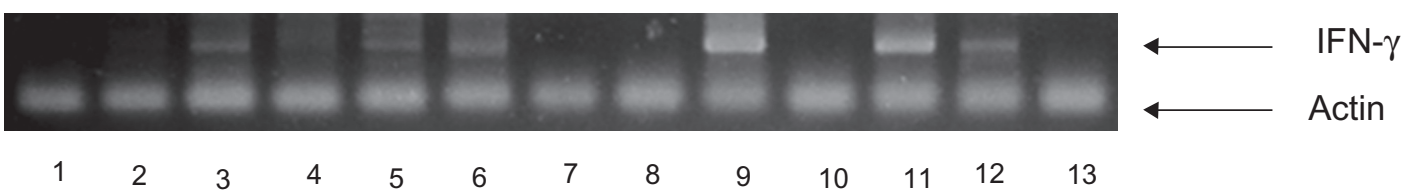

Figure 3 VSV23 Produces Active IL-23. A) vlL23 production by VSV23 infected BHK2I cells. BHK2I cells were infected with VSV23, VSVST, or VSVXN2 at MOI = 0.I and incubated overnight at $37{ }^{\circ} \mathrm{C}$.Virally infected supernatant was harvested and subjected to UV inactivation to inactivate virus. Supernatant from uninfected BHK2I cells was used as a negative control. Samples were subjected to the Quantikine Mouse IL-I2/IL-23 p40 (non-allele-specific) Immunoassay ELISA kit (R\&D Systems Minneapolis, MN). Supernatant from VSV23 infected cells contained $750 \mathrm{pg} / \mathrm{ml}$ of the $\mathrm{p} 40$ subunit. The experiment indicates that there are no detectable levels of $\mathrm{p} 40$ secreted by cells infected with VSVST orVSVXN2. BHK2I cells do not produce IL-23 and as expected control samples did not produce detectable levels of the cytokine component. B) IFN- $\gamma$ is induced by IL-23: Lanes represent amplified mRNA specific for IFN- $\gamma$ from CD4+ cells that were treated as follows - I: rIL- 12 for 6 hours, 2: rIL-23 for 6 hours, 3: rIL- 12 for I 2 hours, 4 : rIL-23 for 12 hours, 5: rIL- 12 for 18 hours, 6: rlL-23 for 18 hours,7:vlL- 12 for 6 hours, 8 : vIL-23 6 hours, 9: vlL- 12 for 12 hours, 10 : vIL-23 for 12 hours, II:vlL- 12 for 18 hours, 12: vIL-23 for 18 hours, 13: untreated CD4+ T cells. Upper band represents IFN- $\gamma$ signal at 400 bp, lower band is GAPDH loading control at 200 bp. Each reaction was run in triplicate, and the experiment was repeated twice. Image is typical of all results.

Abbreviations: IFN, interferon; mRNA, messenger ribonucleic acid.

IL-12 treated cells showed IFN- $\gamma$ mRNA expression at 12 and 18 hours (lanes 3 and 5, respectively, Figure 3B), but IL-23 treated cells only showed a positive signal at 18 hours (lane 6). vIL-12 treatment induced a strong signal at 12 and 18 hours (lanes 9 and 11, respectively), while vIL-23 treated cells again induced IFN- $\gamma$ message at 18 hours (lane 12). Data presented are representative of three replicate experiments. From this we conclude the VSV23 does encode a functional IL-23 cytokine.

\section{VSV23 induces robust immune responses in the periphery}

Use of VSV23 as an oncolytic agent requires that the virus be capable of inducing immune responses necessary to protect noncancerous tissues from viral infection. Immunization of groups of mice with the panel of viruses was performed to determine if VSV23 were immunogenic in vivo following parenteral exposure. Subsequently, we evaluated nonantigen restricted innate immune responses, as well as antigenspecific targeted CTL and memory responses, and antibody production induced by VSV23 inoculation and infection.

\section{NK assay}

Viral infection or immunization is one of the most effective ways to induce NK cells, an innate immune response to infection which is not antigen-specific nor histocompatibilityrestricted. ${ }^{62} \mathrm{NK}$ lytic activity can be quantified by measuring lysis of sensitive cells such as YAC-1. ${ }^{63} \mathrm{NK}$ activation was 
tested 3 days post-inoculation with the panel of viruses. Splenocytes from individual donors were tested separately. Both mock and uninfected splenocytes showed similar background levels of cell lysis indicating no NK mediated cell killing in either of these infection groups (Figure 4A). Data are representative of 3 replicate experiments; data are expressed as means \pm standard deviation of 6 individuals per group. The NK cytolytic responses elicited by VSV23 inoculation were indistinguishable from those induced by VSVST, VSVXN2, and VSVwt.

\section{CTL assay}

The ability of viruses to elicit host CTL responses which control infection and promote recovery is a hallmark of host acquired immunity to infection. A secondary CTL experiment was conducted to determine VSV specific recognition of syngeneic target cells 20 days after immunization of mice with the panel of viruses. There was no lysis of uninfected A20 cells, and virus infection of stimulator cells was required to induce CTL activity (data not shown). All splenocytes cultured with VSV tsG41(a temperature

B

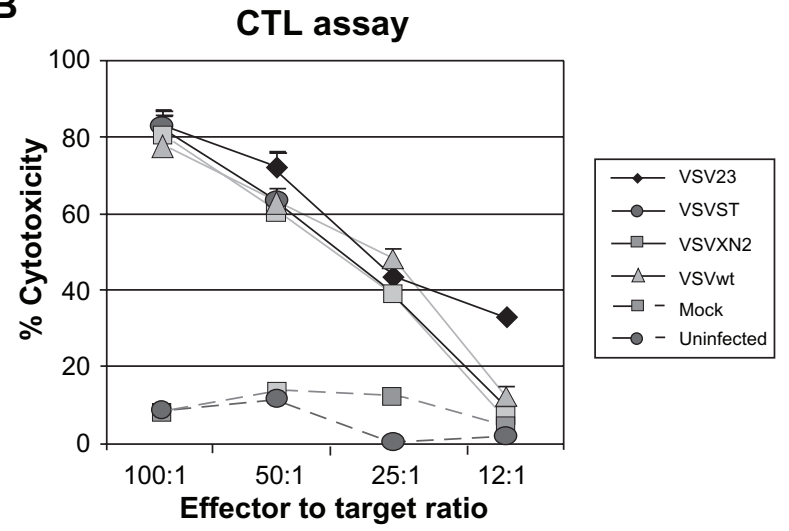

D

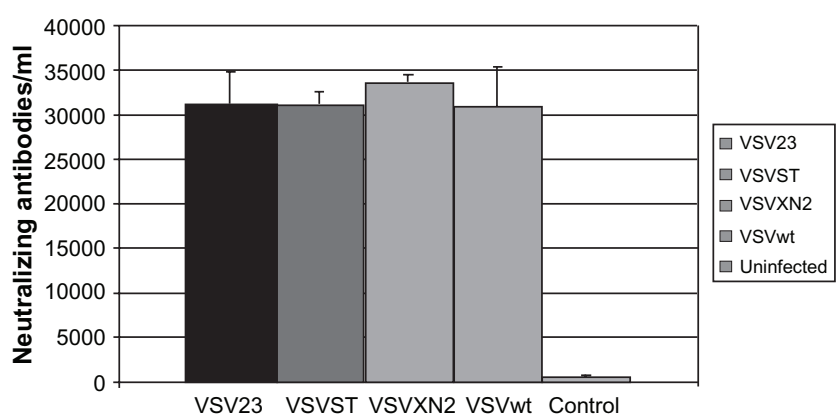

Figure 4 Innate and adaptive immune responses to VSV23. A) Natural killer cell activation: Cohorts of $N=6$ week old male BALB/c mice were inoculated ip with I $\times 10^{7}$ pfu of VSV23 (diamond),VSVST (circle),VSVXN2 (square),VSVwt (triangle), or vehicle (square and dashed line). Uninfected animals were used as a control (circle and dashed line). Splenocytes were harvested 3 days later and co-incubated with YAC-I cells. Cytolytic activity was determined using the CytoTox $96^{\circledR}$ NonRadioactive Cytotoxicity Assay from Promega. All samples from virally inoculated animals showed similar levels of NK mediated cell killing. Data presented are means \pm standard deviation and are representative of three replicate experiments. B) Memory response against VSV is shown in splenocytes targeted to VSV infected A20 cells: Cohorts of $N=6$ week old male $\mathrm{BALB} / \mathrm{c}$ mice were injected ip with $\mathrm{I} \times 10^{7}$ pfu of VSV23 (diamond), VSVST (circle), VSVXN2 (square), VSVwt (triangle), or mock infected (square and dashed line). Cultured $T$ cells from uninfected animals were used as a negative control (circle and dashed line). 20 days post inoculation, splenocytes were harvested and cultured with stimulator splenocytes either infected with VSVtsG4I or uninfected (data not shown). After 5 days of incubation, cells were incubated with A20 tumor cells that were either infected with tsG4I or not infected.All splenocytes cultured with ts G4I infected stimulators exhibited cytolytic activity against infected A20 cells, indicative of a memory response against VSV. Data presented are means \pm standard deviation and are representative of three replicate experiments. C) All virus-immune T cell populations show T cell proliferation when cultured with infected stimulators. Cohorts of $N=6,6$ week old male BALB/c mice were inoculated ip with I $\times 10^{7}$ pfu of VSV23, VSVST,VSVXN2, VSVwt, or mock infected. Uninfected animals were used as a control. Twenty days after immunization, splenocytes were harvested and cultured with syngeneic stimulator splenocytes that were infected with VSVtsG4I (at the permissive temperature, $3 \mathrm{I}{ }^{\circ} \mathrm{C}$; left panel) at a ratio of I:I.Triplicate cultures were incubated for 3 days. T cell proliferation was then measured using the BrdU ELISA Assay Kit from Roche Applied Science. Data are presented as mean \pm standard deviation. All splenocytes cultured with VSVtsG4I-infected stimulators showed similar levels of T cell proliferation, while those cultured with uninfected stimulators (data not shown) indicated no proliferation above the background of mock-infected or uninfected control CD4 $4^{+}$cells (data not shown). Data presented are means \pm standard deviation. The experiment shown is one of three replicate studies, with comparable results. D) Neutralizing antibodies are present 20 days post infection. Cohorts of $N=6$ week old male BALB/c mice were infected in with I $\times 10^{3}$ pfu of VSV23,VSVST,VSVXN2, or VSVwt. Uninfected animals were used as a control. Blood samples were collected 20 days post infection. Serum was isolated and serial five-fold dilutions were made. $1 \times 10^{3} \mathrm{pfu}$ of each virus was co-incubated with the serum from the matching treatment group for one hour. Samples were then used to infect L929 cells and plaque assays were subsequently performed and used to determine antibody titer. Data presented are geometric means \pm standard deviation and are representative of three replicate experiments. All viral treatment groups showed similar levels of neutralizing antibodies to rVSVs. 
sensitive VSV mutant) infected stimulators developed CTL activity against VSV-infected A20 cells, indicative of a memory response against VSV (Figure 4B). Data shown are representative of 3 replicate experiments and are expressed as means \pm standard deviation of 6 individuals per condition. This experiment indicated that VSV23 was capable of inducing VSV-specific memory CTLs.

\section{Proliferation assay}

The ability of viruses to induce memory specific Th1 cell responses is often measured by the induction of antigenspecific proliferating cells with syngeneic antigen presenting cells (APCs). A proliferative response to VSV antigens by $\mathrm{T}$ cells was determined for the panel of viruses twenty days after injection. The ability of VSV23 and control viruses to induce memory responses was indistinguishable from VSVwt (Figure 4C). All responder CD4 ${ }^{+} \mathrm{T}$ cells incubated in the absence of VSVtsG41 showed no proliferation above background, similar to that seen in cells from naïve mice with VSV-infected APCs (data not shown). The data shown are representative of 3 replicate experiments. Data are expressed as means \pm standard deviation of 6 individuals per condition. We interpret these data to indicate that VSV23 induced a robust $\mathrm{CD} 4^{+}$memory response.

\section{Neutralizing antibody assay}

The ability to induce the production of neutralizing antibody is critical for protection against secondary viral infections. Groups of mice were infected IN with the panel of the viruses, and surviving individuals were bled twenty days after immunization to obtain serum. Serum of individual donors was diluted in PBS in serial five-fold steps. $1 \times 10^{3}$ pfu of VSVwt in PBS was added to each dilution and all samples were allowed to incubate for 1 hour before adsorption to L929 monolayers. Three replicate experiments were performed with similar results. Data are expressed as means \pm standard deviation of six individuals per group. All 4 virus immunizations produced similar results (Figure 4D), which indicated that VSV23 was able to stimulate the production of neutralizing antibodies against VSVwt.

\section{VSV23 is attenuated for encephalitis and induces no responses}

A potential concern regarding the use of VSV as an oncolytic agent is the characteristic encephalitis that results from infection of the CNS in immunocompetent mice. Administration of VSV IN results in infection of olfactory sensory neurons in the nasal turbinates. The infection spreads along the olfactory nerve to the olfactory bulb and then caudally through synapses. Once VSV reaches the olfactory ventricle, virus spreads in cerebral spinal fluid to motor neurons in the lumbar-sacral spinal cord, giving rise to the symptoms of encephalitis and hind-limb paralysis in the infected animal. ${ }^{16,64,65}$

The ability of VSV23 to cause disease in mice when administered IN (the route which readily leads to viral encephalitis) was studied. VSV23 was compared with the rVSV controls and VSVwt for the ability to cause illness and death. Specific immune responses in the CNS in response to infection, as well as resultant viral titers, were determined.

\section{Decreased morbidity and mortality at $\mathrm{I} \times 10^{4} \mathrm{pfu}$}

Cohorts of mice were infected IN with the panel of viruses and examined daily (by an observer who was blinded to the challenge viruses) for 15 days to monitor for weight loss and health. Hind-limb paralysis or weight loss that exceeded $30 \%$ of starting weight were considered end points for individuals in the experiment. Three replicate experiments indicated that VSV23 was completely attenuated in the CNS at $1 \times 10^{4}$ pfu. Mice receiving the recombinant viruses at those doses exhibited 20\% mortality while mice infected with VSVwt exhibited 70\% mortality (Figure 5). Kaplan-Meier survival curve analysis indicated that VSV23 was different from the other rVSVs by $\mathrm{p}<0.05$ and from VSVwt by $\mathrm{p}<0.005$.

\section{Decreased morbidity and mortality at $\mathrm{I} \times 10^{6} \mathrm{pfu}$}

To determine the extent and mechanism of attenuation, the infection was performed at a much higher challenge, $1 \times 10^{6} \mathrm{pfu}$. This dose was chosen based on pilot studies utilizing increasing log doses to determine the minimum pfu of VSV23 that could induce mortality.

Cohorts of mice were infected IN with the panel of viruses and examined daily (by an observer who was blinded to the challenge viruses) for 15 days to monitor for weight loss and health. Hind-limb paralysis or weight loss that exceeded $30 \%$ of starting weight were considered end points for individuals in the experiment. The nonparametric Kruskal-Wallis analysis of symptom data showed a significant difference in clinical scores among the groups $(\mathrm{p}<0.05)$, indicative of the decreased morbidity characteristic of VSV23 infection (Figure 6A). Analysis of average percentage weight loss for all groups indicated no significant difference in weight among all infection groups (Figure 6B). VSV23 infection resulted in $25 \%$ mortality. Infection with VSVST and VSVXN2 resulted in $40 \%$ and $58 \%$ mortality, respectively (Figure 6C). Kaplan-Meier survival curve analysis utilizing the one-tail 


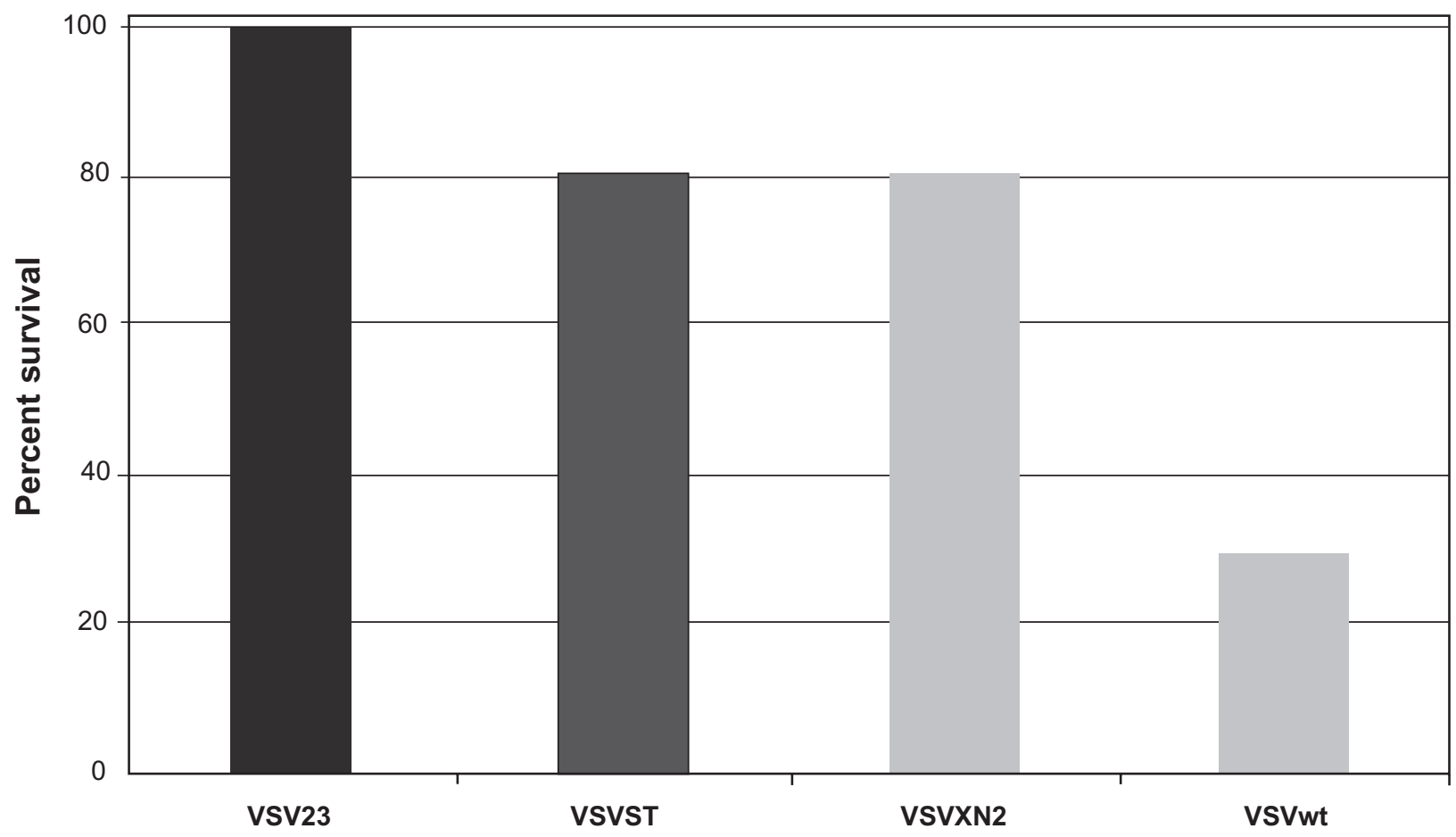

Figure 5 VSV23 infection is attenuated for lethal intranasal infection resulting in viral encephalitis at I $\times 104$ pfu: Cohorts of $N=10,6$-week old BALB/c mice were infected intranasally with $1 \times 10^{4}$ pfu ofVSV23,VSVST,VSVXN2, orVSVwt and monitored for 15 days.VSV23 infection resulted in no mortality, VSVST infection resulted in $20 \%$ mortality, VSVXN2 infection resulted in $20 \%$ mortality, and VSVwt resulted in $70 \%$ mortality. VSV23 is different from the other recombinant viruses by $\mathrm{P}<0.05$ and from VSVwt by $\mathrm{P}<0.005$ in Kaplan Meier analysis. Results were identical in three replicate experiments.

$\mathrm{p}$ value indicated that VSV23 was different from the other viruses by $\mathrm{p}<0.05$. Taken together, these experiments indicate that VSV23 is attenuated for both morbidity and mortality in mice.

\section{VSV23 titers in the CNS}

A simple way to quantify the degree of VSV23 attenuation is to measure viral titers in the brains of infected animals. Mice were infected IN with the panel of viruses and on days 1, 3, 6 , and 9 after infection, virus present in homogenates of brain tissue from individuals were tested by plaque assay. Viral titers of VSV23 infected mice were approximately 10- to 100-fold less than both VSVST and VSVXN2 at all time-points in the CNS after IN infection with $1 \times 10^{3}$ pfu (Figure 7A). Brains of animals infected with $1 \times 10^{6} \mathrm{pfu}$ of VSV23 contained similar viral titers on days 1 and 3 PI compared to control viruses (Figure 7B). We interpret this to indicate that at the lower challenges, the secretion of IL-23 enhanced the attenuation of the virus infection of neurons.

\section{VSV23 infection of the CNS induces increased levels of nitric oxide}

Studies have shown that production of nitric oxide (NO) in the CNS promotes survival and recovery from VSV encephalitis. ${ }^{66-68}$
In addition, IL-12 promotes rapid containment of virus in the CNS and enhanced survival. ${ }^{69-71}$ In experiments in vitro, VSV23, but not the other viruses induced neuronal cells (but not fibroblasts) to produce $\mathrm{NO}$ which subsequently suppressed viral replication (data not shown). Therefore, it was important to determine if VSV23 were able to induce the production of NO in vivo during infection of the CNS. Mice were infected IN with the panel of viruses and on days 1, 3, 6, and 9 after infection, homogenates of brain tissue from individuals were examined for the presence of NO by a colorimetric test, the Greiss assay. Although there was no significant increase in NO levels day 1 PI, by day 3 VSV23 infection resulted in significantly increased NO levels, at both infection doses. Measurement of NO levels indicated a significant increase in NO in VSV23 infected animals compared to control viruses after infection with $1 \times 10^{6} \mathrm{pfu}$ VSV23, $\mathrm{p}<0.05$ as determined by ANOVA analysis (Figure 7C). We interpret these data to be compatible with the hypothesis that IL-23 induces nitric oxide synthase (NOS) activation and NO production in vivo.

\section{VSV23 replicates in tumor cells in vitro and induces apoptosis}

VSV infection of susceptible cells rapidly leads to apoptosis due to both blockade of the nuclear pore complex and direct 
A

$1 \times 10^{-6}$ L.N. infection clinical scores
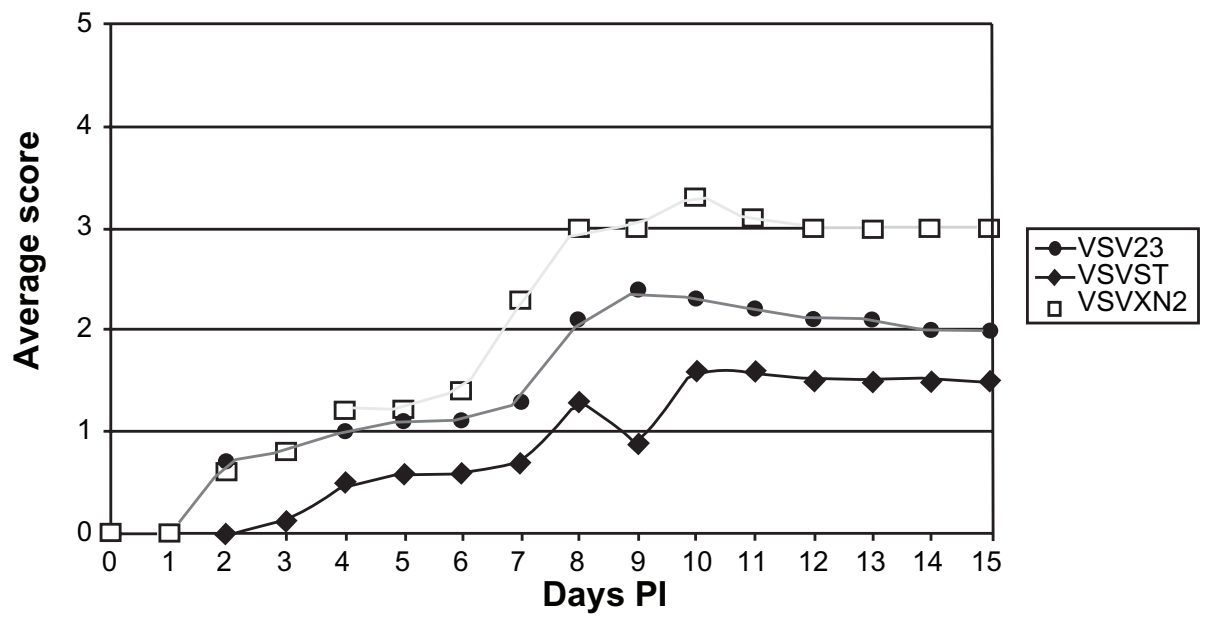

B

$1 \times 10^{-6}$ L.N. infection percent weight loss
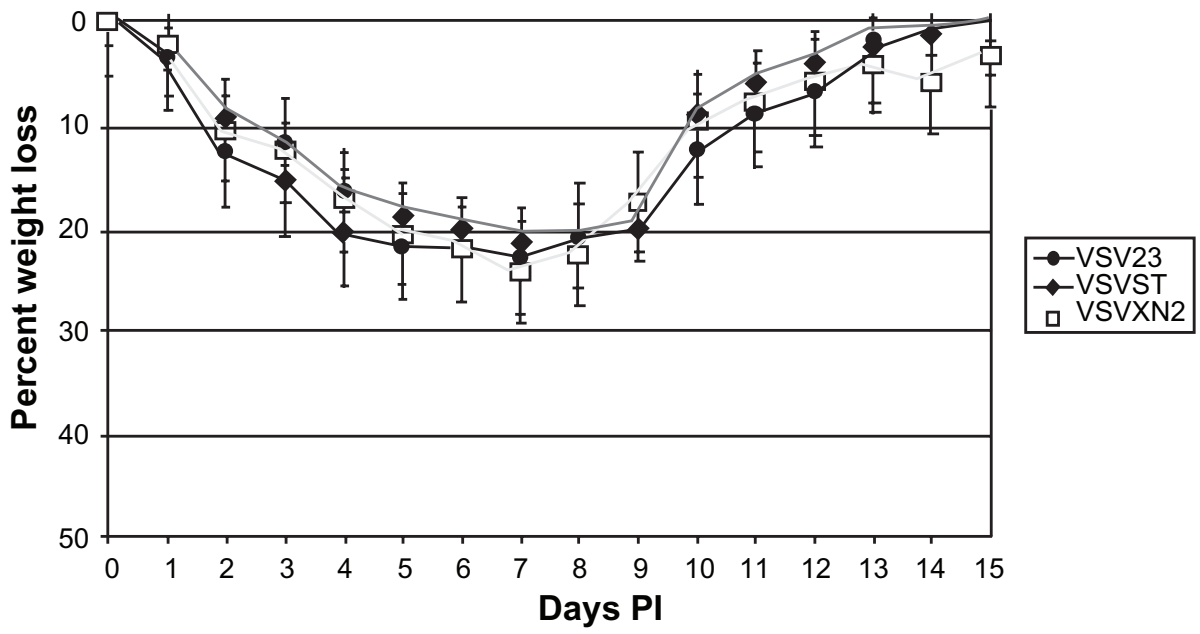

C

Survival curve

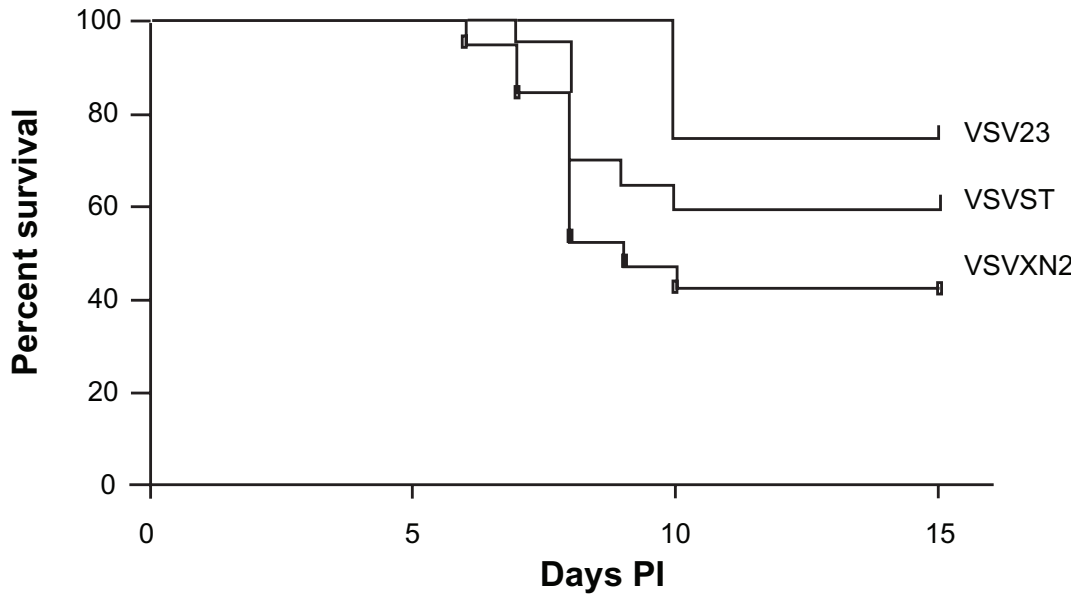

Figure 6 VSV23 infection is attenuated for lethal intranasal infection resulting in viral encephalitis at I $\times 106$ pfu: Cohorts of $N=10,6$-week old BALB/c mice were infected intranasally with $1 \times 10^{6}$ pfu of VSV23,VSVST, or VSVXN2 and monitored for 15 days. A) Morbidity: Mice were weighed and scored daily to assess clinical symptoms: "I" for lack of grooming behavior,"2" for hunched and severely lethargic mice," 3 " for hind-limb paralysis and "4" for full paralysis, "5" for death. Each data point represents the average score of the cohort. Kruskal-Wallis analysis of symptom data indicated thatVSV23 exhibited a significant difference in clinical scores p $<0.05$. B) Weight-loss: Weight-loss was comparable for all infection groups and is presented as mean \pm standard deviation. C) Mortality: VSV23 infection resulted in $25 \%$ mortality, VSVST infection resulted in $40 \%$ mortality, VSVXN2 infection resulted in 58\% mortality. VSV23 is different from the other viruses by $p<0.05$ in Kaplan Meier analysis. Abbreviation: $\mathrm{PI}$, postinfection. 


\section{A $1 \times 10^{3} \mathrm{pfu}$}

Brain viral titers: Day 1

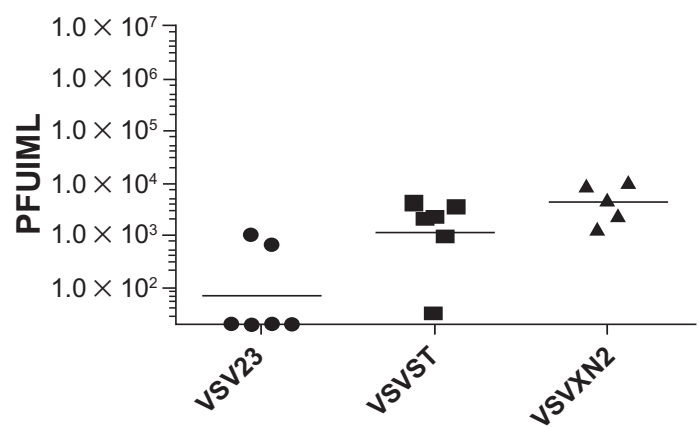

B $1 \times 10^{6} \mathrm{pfu}$

Brain viral titers: Day 1

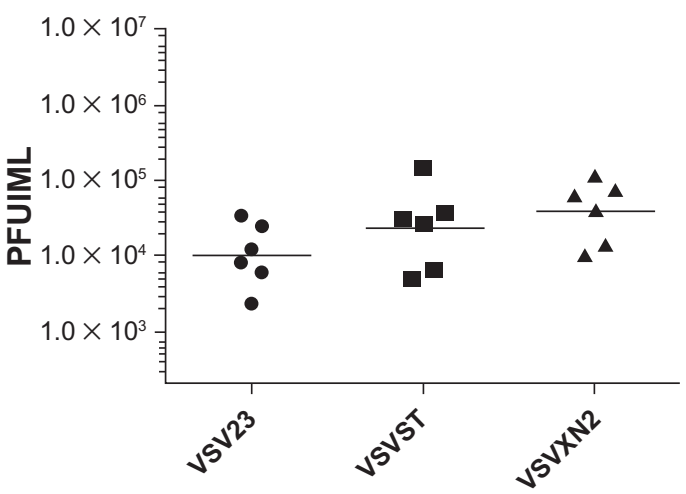

Brain viral titers: Day 3

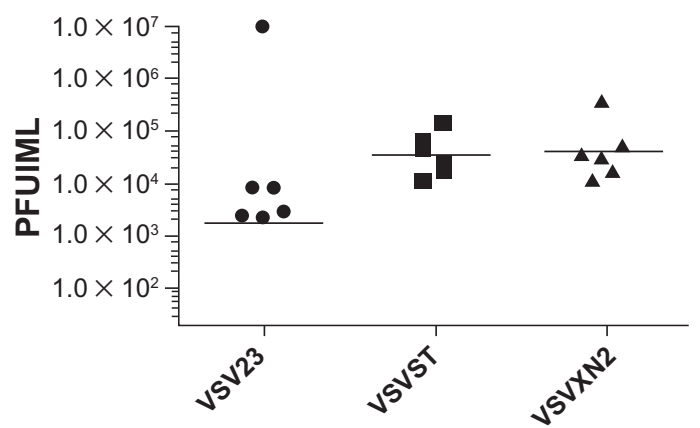

Brain viral titers: Day 3

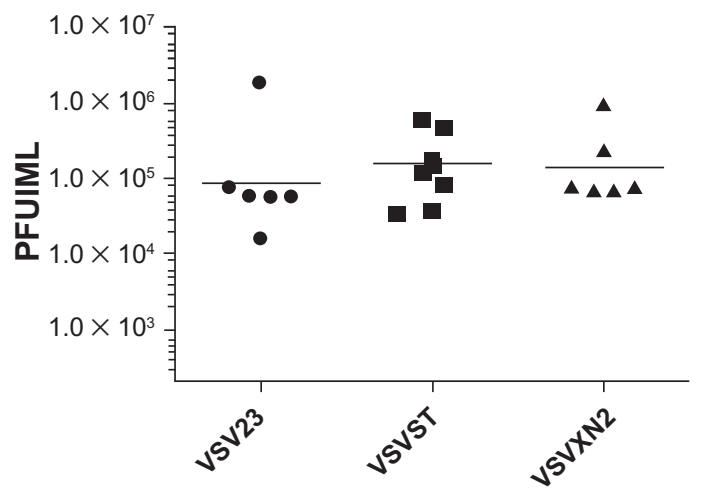

C

Brain: Nitric Oxide

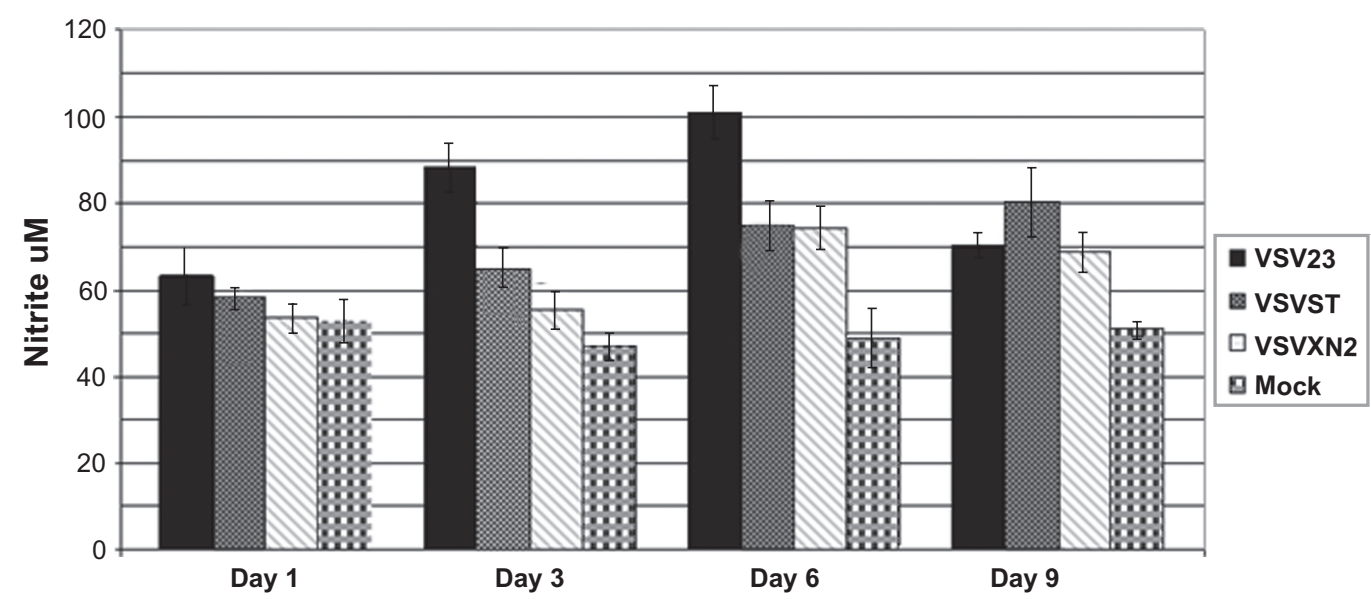

Figure 7 rVSV viral titers and NO production following intranasal infection: A) Viral titers at I $\times 103$ pfu: Cohorts of $\mathrm{N}=6,6$ week old male BALB/c mice were infected in with I $\times 10^{3}$ pfu of VSV23, VSVST, or VSVXN2. Brains were harvested on days I, and 3 p.i., divided into hemispheres sagitally, and one half was homogenized. Samples were serially diluted and plated on $\mathrm{L} 929$ cells. Plaque assays were performed cells to determine viral titers. Data points represent titers in individual mice. Horizontal bars indicate the geometric mean titer of the cohorts.VSV23 titers as represented by the geometric mean were at least I log lower than all other viral treatment groups at both time points. B) Viral titers at I $\times 106$ pfu:The experiment out lined above was repeated, but mice were infected in with I $\times 10^{6}$ pfu of VSV23,VSVST, or VSVXN2. Results were similar for all infections at both time points. Data shown are representative of 3 identical experiments. C) NO levels in the central nervous system: Brains were harvested on days I, 3,6, and 9 p.i. after infection withVSV23 (solid bars),VSVST (stipled bars),VSVXN2 (slashed bars), or mock infected (plaid bars) and homogenates were tested for the presence of NO using the Greiss assay.VSV23 induces greater amounts of NO compared to other rVSVs and does so at earlier time points. Data shown are means \pm standard deviations. ANOVA analysis of days 3 and 6 data reject the null hypothesis with $p<0.05$. This figure is representative of data from three identical experiments.

Abbreviation: NO, nitric oxide. 
interactions with the mitochondria. ${ }^{6-8,72}$ In order to test the ability of VSV23 to infect and kill tumor cells, the panel of viruses was used in an in vitro growth study in a murine mammary derived JC tumor line. Cells were infected and an assay of apoptosis, the MTT assay, was conducted at 3, 6, 9, 12, 18, and 24 hours PI. Experimental results (Figure 8) indicated that VSV23 replicated and induced JC cell death that was indistinguishable from control rVSVs and VSVwt.

\section{Discussion}

VSV selectively destroys a wide variety of tumor cell lines including those with aberrant p53, Ras, or Myc function such as glioblastomas ${ }^{10,73,74}$ colorectal, pancreatic, and breast cancer cells. ${ }^{24,75-77}$ Other targets of VSV therapy include leukemia, hepatocellular carcinoma, nasopharyngeal carcinoma, and bladder cancer. ${ }^{75,78-85}$ Several characteristics of VSV make it particularly attractive as a candidate for development as an oncolytic virus. VSV has a rapid replication cycle and infection with VSV is generally both asymptomatic and very rare in humans. ${ }^{86}$ Potentially, VSV could replicate and exert its oncolytic effects prior to host development of a neutralizing serological response. ${ }^{75}$ Finally, the virus can easily be genetically engineered to express transgenes..$^{59,87-90}$
However, administration of therapeutic doses of VSV in mice can lead to substantial "toxicities" including hind-limb paralysis and death. ${ }^{10,24}$ The need to create a safer oncolytic agent and our extensive prior studies on the pathogenesis of VSV encephalitis led to the hypothesis that a rVSV that expresses IL-23 would attenuate the virus in healthy tissue while maintaining and possibly enhancing oncolytic activity. ${ }^{16,26,65,91-93}$

This hypothesis was based on several lines of research. In studies of VSV encephalitis, treatment of mice with IL-12 enhances viral clearance and survival. ${ }^{70,71,94}$ Unfortunately, administration of IL-12 in phase II clinical oncology trials has been associated with severe toxicity and death, partly due to the induction of high levels of IFN- $\gamma \cdot{ }^{53,54}$ Since IL-23 and IL-12 share the functional p40 subunit and a receptor chain component, IL-12R $\beta 1$, IL-23 was anticipated to act in similar manner, however with reduced deleterious effects. This is due to the fact that IL-23 induces lower levels of IFN- $\gamma$ than IL-12. ${ }^{43}$ Additionally, IL-23 is expressed in the CNS during inflammation. ${ }^{43,46,95}$ Finally, IL-23 has been reported to have antimetastatic and antitumor properties. ${ }^{49,52,55-57,96}$ Experiments in murine mammary cancer cells have shown that these IL-23 effects are mediated by increasing numbers of $\mathrm{CD}^{+}$ $\mathrm{T}$ cells and induction of tumor specific $\mathrm{CD} 8^{+} \mathrm{T}$ cells. ${ }^{57}$

\section{MIT assay $\mathrm{MOI}=3$}

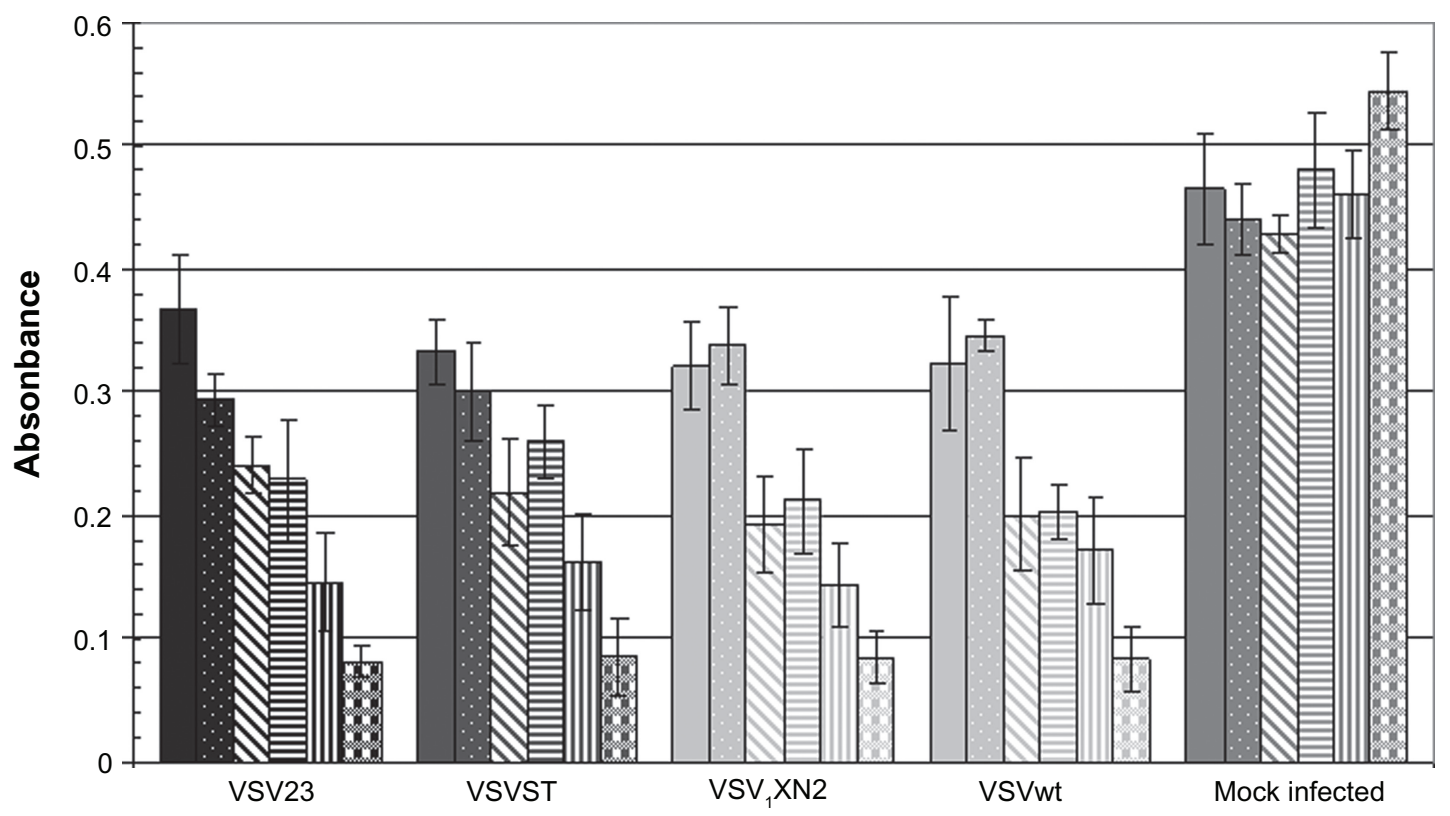

Viral infection: $3,6,9,12,18,24 \mathrm{hr}$

Figure 8 Infection with VSV23 andVSVXN2 induces mitochondrial dysfunction in JC cells: $4.5 \times 10^{4} \mathrm{JC}$ cells were plated in 96-well plates and incubated overnight. Cells were then infected at MOI = 3 and incubated for 3 (solid bars), 6 (stipled bars), 9 (slashed bars), 12 (horizontal striped bars), 18 (vertically striped bars), or 24 (plaid bars) hours with VSV23, VSVST, VSVXN2, VSVwt, or mock treated. MTT reagent was added per manufacturer's instructions and samples were incubated at RT in the absence of light for 4 hours. Plates were read on an ELISA plate reader at $540 \mathrm{~nm}$. All viruses are capable of disrupting mitochondrial function. Data are presented as mean \pm standard deviation and are representative of the replicate experiments. Abbreviation: RT, room temperature. 
We presented data showing that a rVSV, designated VSV23, expresses functionally active IL-23 and maintains replicative capacity. A concern in using a scIL-23 cDNA is that translation of the subsequent mRNA might not result in an active protein. However, virally produced IL-23 readily induced IFN- $\gamma \mathrm{mRNA}$ in $\mathrm{CD} 4^{+} \mathrm{T}$ cells (Figure $3 \mathrm{~B}$ ). Addition of $1.3 \mathrm{~kb}$ of RNA into the VSV genome could have resulted in significant deficiencies in viral replication; however one-step growth curve data showing similar viral titers between control viruses and VSV23 ameliorated this concern (Figure 2).

In order for VSV23 to be a safe oncolytic agent, the virus must be capable of inducing innate and adaptive host immune responses in order to prevent infection of the CNS and subsequently inducing encephalitis. Bystander effects including cellular immunity and antitumor responses that result in tumor destruction caused by VSV23 infection are also hypothesized to be beneficial in the treatment of cancer. To determine if VSV23 were sufficiently immunogenic, a series of experiments were conducted to examine innate and adaptive immune responses.

Innate NK cell activity does not require exposure to a specific antigen in order to elicit a cytolytic response. ${ }^{63}$ Activation only requires local immune responses that stimulate IFN- $\gamma$, IL-12, and other cytokines that result in positive regulation of NK cells. ${ }^{97}$ Inoculation of mice with VSV23 induced similar levels of NK mediated YAC cell killing three days PI compared to control rVSVs and VSVwt (Figure 4A). Studies have shown that IL-23 takes up to 2 weeks after the initiation of treatment to enhance the effect of NK cells. ${ }^{49}$

Adaptive immune responses to viral infection can be detected in mice as early as 7 days PI. Memory responses in mice inoculated with the panel of viruses were assayed twenty days after inoculation and were indistinguishable (Figs 4B-D). Studies using unprimed lymphocytes indicated no memory response. This was due to insufficient precursors in naïve mice. There was a similar level of memory responses in VSV23 primed mice as indicated by comparable levels of CTL activity at all effector-to-target ratios. The proliferation of $\mathrm{T}$ cells is an important property of the adaptive immune system. ${ }^{98}$ The proliferative response to the VSV antigens by $\mathrm{CD} 4^{+} \mathrm{T}$ cells was determined. As expected, all virus-primed splenocytes cultured with VSV tsG41-infected stimulators showed similar levels of $\mathrm{T}$ cell proliferation (Figure 4B). In addition to cell mediated responses to viral inoculation, we examined the production of neutralizing antibodies after IN infection. Twenty days PI, comparable levels of neutralizing antibodies were detected in blood serum of infected animals (Figure 4D).
The results of assessments of adaptive immunity to VSV indicated that there was no difference in the ability of any of the viruses to induce adaptive immune responses. There was a possibility that vIL-23 would induce altered $\mathrm{T}$ cell responses. The fact that no differences in CTL killing, T cell proliferation, nor neutralizing antibody titers were observed could be explained by rapid viral clearance. There was simply insufficient time to produce biologically relevant levels of vIL-23 following IP inoculation. In the case of antibody production, vIL23 did not enhance B cell clones specific for VSV. Alternatively, it is possible that the antibody responses to other viral antigens were altered but undetected as we only assessed neutralizing antibody.

In vivo studies showed that VSV23 is attenuated for induction of viral encephalitis compared to control rVSVs and VSVwt. These results are consistent with previous findings that recombinant versions of VSV show greater attenuation in vivo compared to VSVwt. ${ }^{99-101}$ The reasons for attenuation are likely deletions and nucleotide variations characteristic of the cloned version of VSV. ${ }^{59}$ In order to control for the inherent differences in rVSVs compared to VSVwt we utilized VSVXN2, a rVSV carrying no insert at the cloning site. VSVST was created to control for alterations in genome, and hence particle size associated with insertion of scIL-23. Stop codons were introduced into the $\mathrm{p} 40$ subunit coding region of IL-23, but not the p19 subunit. Infection of mice with VSV23 led to decreased morbidity and mortality compared to mice infected with control viruses at a very high challenge dose (Figure 6A-C), but virtually none at lower challenges (data not shown) indicating that the attenuation of VSV23 can be attributed to the effects of vIL-23. Despite increased survival (Figures 5 and 6C) and milder symptoms in VSV23 infected mice (Figure 6 A, B), no difference was seen in weight loss indicating that infection with VSV23 results in some morbidity. This may be due to transient destruction of the olfactory neuroepithelium leading to a decrease in olfactory function and hence decreased feeding activity. ${ }^{65}$ Minor differences in the attenuation of VSVST compared to VSVXN2 are likely due to morphological and metabolic alterations associated with the additional genomic load. Alternatively, it is possible (but unlikely) that residual expression of p19 might have led to induction of IFN- $\gamma$ resulting in some attenuation in vivo. ${ }^{43}$

Measurement of viral titers in the CNS revealed a significant decrease in VSV23 compared to control viruses after infection with $1 \times 10^{3}$ pfu (Figure $7 \mathrm{~A}$ ). Animals infected with $1 \times 10^{6}$ pfu of VSV23 had less morbidity and mortality, however this did not correlate to a decrease in viral titers on 
days 1 and 3 PI (Figure 7B). It is possible that at this early stage in the infection innate immune responses are being overwhelmed, but are subsequently capable of controlling the infection at later time points. Another hypothesis is that the spread of the virus in the CNS is limited in VSV23-infected animals. This would allow for high viral titers without infection of caudal regions of the brain. Work is in progress to address this question.

We hypothesized that vIL-23 may share the ability of IL-12 to induce NOS in the CNS, resulting in enhanced NO production. ${ }^{67,92,102}$ This would provide a plausible mechanism of attenuation. After infection with $1 \times 10^{3}$ and $1 \times 10^{6}$ pfu there was no significant increase in NO levels day 1 PI as determined by the Greiss assay. However, by day 3 PI significantly increased levels were detected (Figure 7B). Preliminary immunohistological analysis of sections from the olfactory bulbs of infected animals show that NOSII expressing microglia were present in VSV23 infected mice as early as 1 day PI, but not in other infections until day 6 PI (data not shown). As such, increased levels of NOS II expressing cells between days 1 and 3 PI are likely to be responsible for the increase in NO levels in brain homogenates. Work continues at this time to determine whether increased NO levels can be attributed to any particular isoform of NOS in the CNS.

The purpose of creating VSV23 was to develop the virus as an oncolytic agent a vaccine carrier. To study the antitumor effects of the virus we have chosen the JC tumor cell, a murine mammary tumor cell line. In vitro, the ability of VSV23 to induce apoptosis in JC cells is indistinguishable from control rVSVs and VSVwt. Work is in progress to determine the whether VSV23 destroys tumors in vivo. Ideally vIL-23 produced within the tumor will induce a proinflammatory state that would increase oncolytic activity of the virus resulting in enhanced rates of tumor destruction. We will also determine if long-term memory responses are elicited specifically against JC tumor cells as a result of vIL-23. Examination of tumors to detect viral antigens and infiltrating immune cells will also help to determine the potential of VSV23 as an effective tumor treatment.

In conclusion VSV23 is an attenuated virus in vivo, but not in vitro. In the CNS, VSV23 infection is characterized by decreased morbidity and mortality, likely through the induction of early NO responses. In the periphery VSV23 promotes a strong antigenic response based on the results of the virus-specific proliferation, CTL, neutralizing antibody, and NK assays. In vitro VSV23 is capable of inducing apoptosis in tumor cells. This oncolytic capacity coupled with attenuation in the CNS makes VSV23 an attractive agent for further study as on oncolytic virus.

\section{Acknowledgments}

We are grateful for the generous gifts of essential reagents by Maria Louise Belladona (University of Perugia, pCEP4-scIL23Ig plasmid), Jack Rose (Yale, VSVXN2 and helper plasmids), and Savio Woo (Mt Sinai School of Medicine, VSV12). We have benefited by expert advice from Adolfo Garcia-Sastre (Mt Sinai School of Medicine), Savio Woo, Marcia Meseck (then at Mt Sinai School of Medicine), Oliver Ebert (then at Mt Sinai School of Medicine), Daniel Meruelo (NYU School of Medicine) and our colleague Paul M D'Agostino. This work could not have been accomplished without funding from the NIH to CSR, NS039746. The work described in this manuscript has been submitted to the US Patent and Trade Office US Provisional Patent Application Serial \# 61/187,125.

\section{Disclosures}

The authors report no conflicts of interest in this work.

\section{References}

1. Johnson KM, Vogel JE, Peralta PH. Clinical and serological response to laboratory-acquired human infection by Indiana type vesicular stomatitis virus (VSV). Am J Trop Med Hyg. 1966;15:244-246.

2. Fields BN, Hawkins K. Human infection with the virus of vesicular stomatitis during an epizootic. N Engl J Med. 1967;277:989-994.

3. Goodbourn S, Didcock L, Randall RE. Interferons: cell signalling, immune modulation, antiviral response and virus countermeasures. J Gen Virol. 2000;81:2341-2364.

4. Katze MG, He Y, Gale M, Jr. Viruses and interferon: a fight for supremacy. Nat Rev Immunol. 2002;2:675-687.

5. Belkowski LS, Sen GC. Inhibition of vesicular stomatitis viral mRNA synthesis by interferons. J Virol. 1987;61:653-660.

6. Glodowski DR, Petersen JM, Dahlberg JE. Nuclear localization of the Matrix protein of VSV, an inhibitor of nucleocytoplasmic transport. Mol Biol Cell. 2001;12:107a-107a.

7. Petersen JM, Her LS, Varvel V, Lund E, Dahlberg JE. The matrix protein of vesicular stomatitis virus inhibits nucleocytoplasmic transport when it is in the nucleus and associated with nuclear pore complexes. Mol Cell Biol. 2000;20:8590-8601.

8. Ahmed M, McKenzie MO, Puckett S, Hojnacki M, Poliquin L, Lyles DS. Ability of the matrix protein of vesicular stomatitis virus to suppress beta interferon gene expression is genetically correlated with the inhibition of host RNA and protein synthesis. $J$ Virol. 2003;77:4646-4657.

9. Balachandran S, Barber GN. Defective translational control facilitates vesicular stomatitis virus oncolysis. Cancer Cell. 2004;5:51-65.

10. Stojdl DF, Lichty B, Knowles S, et al. Exploiting tumor-specific defects in the interferon pathway with a previously unknown oncolytic virus. Nat Med. 2000;6:821-825.

11. Barber GN. Vesicular stomatitis virus as an oncolytic vector. Viral Immunol. 2004;17:516-527.

12. Connor JH, Naczki C, Koumenis C, Lyles DS. Replication and cytopathic effect of oncolytic vesicular stomatitis virus in hypoxic tumor cells in vitro and in vivo. J Virol. 2004;78:8960-8970.

13. Ahmed M, Cramer SD, Lyles DS. Sensitivity of prostate tumors to wild type and $\mathrm{M}$ protein mutant vesicular stomatitis viruses. Virology. 2004;330:34-49. 
14. Pearce AF, Lyles DS. Vesicular stomatitis virus induces apoptosis primarily through Bak rather than Bax by inactivating Mcl-1 and Bcl-XL. J Virol. 2009;83:9102-9112.

15. Duntsch CD, Zhou Q, Jayakar HR, et al. Recombinant vesicular stomatitis virus vectors as oncolytic agents in the treatment of high-grade gliomas in an organotypic brain tissue slice-glioma coculture model. J Neurosurg. 2004;100:1049-1059.

16. Huneycutt BS, Plakhov IV, Shusterman Z, et al. Distribution of vesicular stomatitis virus proteins in the brains of BALB/c mice following intranasal inoculation: an immunohistochemical analysis. Brain Res. 1994;635:81-95.

17. Reiss CS, Aoki C. Vesicular Stomatitis-Virus - Immune Recognition, Responsiveness, and Pathogenesis of Infection in Mice. Rev Med Virol. 1994;4:129-140.

18. Reiss CS. RNA viruses: host gene responses to infections. Hackensack, NJ: World Scientific, 2009; Chapter 10.

19. Steinhoff U, Muller U, Schertler A, Hengartner H, Aguet M, Zinkernagel RM. Antiviral protection by vesicular stomatitis virus-specific antibodies in alpha/beta interferon receptor-deficient mice. J Virol. 1995;69:2153-2158.

20. Gupta SC, Hengartner H, Zinkernagel RM. Primary antibody responses to a well-defined and unique hapten are not enhanced by preimmunization with carrier: analysis in a viral model. Proc Natl Acad Sci US A. 1986;83:2604-2608.

21. Muller U, Steinhoff U, Reis LFL, et al. Functional-role of type-I and type-II interferons in antiviral defense. Science. 1994;264: 1918-1921.

22. van den Broek MF, Muller U, Huang S, Aguet M, Zinkernagel RM. Antiviral defense in mice lacking both alpha/beta and gamma interferon receptors. J Virol. 1995;69:4792-4796.

23. Durbin JE, Hackenmiller R, Simon MC, Levy DE. Targeted disruption of the mouse Stat1 gene results in compromised innate immunity to viral disease. Cell. 1996;84:443-450.

24. Ebert O, Harbaran S, Shinozaki K, Woo SL. Systemic therapy of experimental breast cancer metastases by mutant vesicular stomatitis virus in immune-competent mice. Cancer Gene Ther. 2005;12:350-358.

25. Forger JM, Bronson RT, Huang AS, Reiss CS. Murine infection by vesicular stomatitis-virus - Initial characterization of the $\mathrm{H}-2 \mathrm{~d}$ system. J Virol. 1991;65:4950-4958.

26. Bi ZB, Barna M, Komatsu T, Reiss CS. Vesicular stomatitis-virus infection of the central-nervous-system activates both innate and acquired immunity. J Virol. 1995;69:6466-6472.

27. Johnson JE, Nasar F, Coleman JW, et al. Neurovirulence properties of recombinant vesicular stomatitis virus vectors in non-human primates. Virology. 2007;360:36-49.

28. Chen N, Restivo A, Reiss CS. Leukotrienes play protective roles early during experimental VSV encephalitis. J Neuroimmunol. 2001;120: 94-102.

29. Reiss CS, Chesler DA, Hodges J, Ireland DD, Chen N. Innate immune responses in viral encephalitis. Curr Top Microbiol Immunol. 2002;265:63-94.

30. Christian AY, Barna M, Bi ZB, Reiss CS. Host immune response to vesicular stomatitis virus infection of the central nervous system in C57BL/6 mice. Viral Immunol. 1996;9:195-205.

31. Diebold SS, Kaisho T, Hemmi H, Akira S, Sousa CRE. Innate antiviral responses by means of TLR7-mediated recognition of single-stranded RNA. Science. 2004;303:1529-1531.

32. Trottier MD, Lyles DS, Reiss CS. Peripheral, but not central nervous system, type I interferon expression in mice in response to intranasal vesicular stomatitis virus infection. J Neurovirol. 2007;13: 433-445.

33. Christian AY, Barna M, Bi Z, Reiss CS. Host immune response to vesicular stomatitis virus infection of the central nervous system in C57BL/6 mice. Viral Immunol. 1996;9:195-205.

34. Bartido SM, Zier K. T-cell responses to multiple antigens presented by RNA-transfected APCs: a possible immunomonitoring tool. Cancer Immunol Immunother. 2004;53:100-109.
35. Browning MJ, Huang AS, Reiss CS. Cytolytic T lymphocytes from the BALB/c-H-2dm2 mouse recognize the vesicular stomatitis virus glycoprotein and are restricted by class II MHC antigens. J Immunol. 1990;145:985-994.

36. Browning M, Reiss CS, Huang AS. The soluble viral glycoprotein of vesicular stomatitis virus efficiently sensitizes target cells for lysis by CD4 $^{+}$T lymphocytes. J Virol. 1990;64:3810-3816.

37. Browning MJ, Huneycutt BS, Huang AS, Reiss CS. Replicationdefective viruses modulate immune responses. J Immunol. 1991;147: 2685-2691.

38. Reiss CS, Gapud CP, Keil W. Newly synthesized class II MHC chains are required for VSV G presentation to CTL clones. Cell Immunol. 1992;139:229-238.

39. Charan S, Hengartner H, Zinkernagel RM. Antibodies against the two serotypes of vesicular stomatitis virus measured by enzyme-linked immunosorbent assay: immunodominance of serotype-specific determinants and induction of asymmetrically cross-reactive antibodies. J Virol. 1987;61:2509-2514.

40. Parham C, Chirica M, Timans J, et al. A receptor for the heterodimeric cytokine IL-23 is composed of IL-12Rbeta1 and a novel cytokine receptor subunit, IL-23R. J Immunol. 2002;168:5699-5708.

41. Bastos KRB, Marinho CRF, Barboza R, Russo M, Alvarez JM, Lima MRD. What kind of message does IL-12/IL-23 bring to macrophages and dendritic cells? Microbes Infect. 2004;6:630-636.

42. Ivanov, II, McKenzie BS, Zhou L, et al. The orphan nuclear receptor RORgammat directs the differentiation program of proinflammatory IL-17+ T helper cells. Cell. 2006;126:1121-1133.

43. Oppmann B, Lesley R, Blom B, et al. Novel p19 protein engages IL-12p40 to form a cytokine, IL-23, with biological activities similar as well as distinct from IL-12. Immunity. 2000;13:715-725.

44. McKenzie BS, Kastelein RA, Cua DJ. Understanding the IL-23-IL-17 immune pathway. Trends Immunol. 2006;27:17-23.

45. Farago B, Magyari L, Safrany E, et al. Functional variants of interleukin-23 receptor gene confer risk for rheumatoid arthritis but not for systemic sclerosis. Ann Rheum Dis. 2008;67:248-250.

46. Becher B, Durell BG, Noelle RJ. IL-23 produced by CNS-resident cells controls $\mathrm{T}$ cell encephalitogenicity during the effector phase of experimental autoimmune encephalomyelitis. J Clin Invest. 2003;112: 1186-1191.

47. Bettelli E, Carrier Y, Gao W, et al. Reciprocal developmental pathways for the generation of pathogenic effector TH17 and regulatory $\mathrm{T}$ cells. Nature. 2006;441:235-238.

48. Kim HR, Cho ML, Kim KW, et al. Up-regulation of IL-23p19 expression in rheumatoid arthritis synovial fibroblasts by IL-17 through PI3kinase-, NF-kappaB- and p38 MAPK-dependent signalling pathways. Rheumatol (Oxf). 2007;46:57-64.

49. Kaiga T, Sato M, Kaneda H, Iwakura Y, Takayama T, Tahara H. Systemic administration of IL-23 induces potent antitumor immunity primarily mediated through Th1-type response in association with the endogenously expressed IL-12. J Immunol. 2007;178:7571-7580.

50. Tahara H, Lotze MT. Antitumor effects of interleukin-12 (IL-12): applications for the immunotherapy and gene therapy of cancer. Gene Ther. 1995;2:96-106.

51. Nastala CL, Edington HD, McKinney TG, et al. Recombinant IL-12 administration induces tumor regression in association with IFN-gamma production. J Immunol. 1994;153:1697-1706.

52. Lo CH, Lee SC, Wu PY, et al. Antitumor and antimetastatic activity of IL-23. J Immunol. 2003;171:600-607.

53. Cohen J. IL-12 deaths: explanation and a puzzle. Science. 1995; 270:908.

54. Car BD, Eng VM, Lipman JM, Anderson TD. The toxicology of interleukin-12: a review. Toxicol Pathol. 1999;27:58-63.

55. Overwijk WW, de Visser KE, Tirion FH, et al. Immunological and antitumor effects of IL-23 as a cancer vaccine adjuvant. J Immunol. 2006;176:5213-5222.

56. Hao JS, Shan BE. Immune enhancement and anti-tumour activity of IL-23. Cancer Immunol Immunother. 2006;55:1426-1431. 
57. Liu L, Shan B, Feng Y. Antitumor effects and immunoregulation mechanisms of IL-23 gene in mouse mammary cancer mediated by retrovirus. Cell Immunol. 2009;258:181-187.

58. Belladonna ML, Renauld JC, Bianchi R, et al. IL-23 and IL-12 have overlapping, but distinct, effects on murine dendritic cells. J Immunol. 2002;168:5448-5454.

59. Lawson ND, Stillman EA, Whitt MA, Rose JK. Recombinant vesicular stomatitis viruses from DNA. Proc Natl Acad Sci U S A. 1995;92: 4477-4481.

60. Shin EJ, Wanna GB, Choi B, et al. Interleukin-12 expression enhances vesicular stomatitis virus oncolytic therapy in murine squamous cell carcinoma. Laryngoscope. 2007;117:210-214.

61. Reiss CS, Chen SS, Huang AS, Doherty R. VSV G protein induces murine cytolytic T lymphocytes. Microb Pathog. 1986;1:261-267.

62. Biron CA. Activation and function of natural killer cell responses during viral infections. Curr Opin Immunol. 1997;9:24-34.

63. Wright SC, Bonavida B. YAC-1 variant clones selected for resistance to natural killer cytotoxic factors are also resistant to natural killer cell-mediated cytotoxicity. Proc Natl Acad Sci U S A. 1983;80 1688-1692.

64. Lundh B, Kristensson K, Norrby E. Selective infections of olfactory and respiratory epithelium by vesicular stomatitis and sendai viruses. Neuropathol Appl Neurobiol. 1987;13:111-122.

65. Plakhov IV, Arlund EE, Aoki C, Reiss CS. The earliest events in vesicular stomatitis virus infection of the murine olfactory neuroepithelium and entry of the central nervous system. Virology. 1995;209:257-262.

66. Bi ZB, Reiss CS. Inhibition of vesicular stomatitis-virus (Vsv) infection by nitric oxide. J Cell Biochem. 1995:305-305.

67. Komatsu T, Bi Z, Reiss CS. Interferon-gamma induced type I nitric oxide synthase activity inhibits viral replication in neurons. J Neuroimmunol. 1996;68:101-108.

68. Barna M, Komatsu T, Reiss CS. Activation of type III nitric oxide synthase in astrocytes following a neurotropic viral infection. Virology. 1996;223:331-343.

69. Bi Z, Quandt P, Komatsu T, Barna M, Reiss CS. IL-12 promotes enhanced recovery from vesicular stomatitis virus infection of the central nervous system. J Immunol. 1995;155:5684-5689.

70. Reiss CS, Komatsu T, Barna M, Bi Z. Interleukin-12 promotes enhanced recovery from viral infection of neurons in the central nervous system. Ann N Y Acad Sci. 1996;795:257-265.

71. Komatsu T, Barna M, Reiss CS. Interleukin-12 promotes recovery from viral encephalitis. Viral Immunol. 1997;10:35-47.

72. Kopecky SA, Willingham MC, Lyles DS. Matrix protein and another viral component contribute to induction of apoptosis in cells infected with vesicular stomatitis virus. J Virol. 2001;75:12169-12181.

73. Balachandran S, Porosnicu M, Barber GN. Oncolytic activity of vesicular stomatitis virus is effective against tumors exhibiting aberrant p53, Ras, or Myc function and involves the induction of apoptosis. J Virol. 2001;75:3474-3479.

74. Huszthy PC, Giroglou T, Tsinkalovsky O, et al. Remission of invasive, cancer stem-like glioblastoma xenografts using lentiviral vectormediated suicide gene therapy. PLoS One. 2009;4:e6314.

75. Huang TG, Ebert O, Shinozaki K, Garcia-Sastre A, Woo SLC Oncolysis of hepatic metastasis of colorectal cancer by recombinant vesicular stomatitis virus in immune-competent mice. Mol Ther. 2003;8: 434-440.

76. Shi W, Tang QQ, Chen XC, et al. Antitumor and antimetastatic activities of vesicular stomatitis virus matrix protein in a murine model of breast cancer. J Mol Med. 2009;87:493-506.

77. Gao Y, Whitaker-Dowling P, Griffin JA, Barmada MA, Bergman I. Recombinant vesicular stomatitis virus targeted to Her2/neu combined with anti-CTLA4 antibody eliminates implanted mammary tumors. Cancer Gene Ther. 2009;16:44-52.

78. Tumilasci VF, Oliere S, Nguyen TLA, Shamy A, Bell J, Hiscott J. Targeting the apoptotic pathway with BCL-2 inhibitors sensitizes primary chronic lymphocytic leukemia cells to vesicular stomatitis virus-induced oncolysis. J Virol. 2008;82:8487-8499.
79. Cesaire R, Oliere S, Sharif-Askari E, et al. Oncolytic activity of vesicular stomatitis virus in primary adult T-cell leukemia. Oncogene. 2006;25:349-358.

80. Shinozaki K, Ebert O, Woo SLC. Treatment of multi-focal colorectal carcinoma metastatic to the liver of immune-competent and syngeneic rats by hepatic artery infusion of oncolytic vesicular stomatitis virus. Int J Cancer. 2005;114:659-664.

81. Shinozaki K, Ebert O, Kournioti C, Tai YS, Woo SLC. Oncolysis of multifocal hepatocellular carcinoma in the rat liver by hepatic artery infusion of vesicular stomatitis virus. Mol Ther. 2004;9: 368-376.

82. Altomonte J, Braren R, Schulz S, et al. Synergistic Antitumor Effects of Transarterial Viroembolization for Multifocal Hepatocellular Carcinoma in Rats. Hepatology. 2008;48:1864-1873.

83. Feng Y, He G, Wu Y, Wen Y. Effect of apoptosis of vesicular stomatitis virus on tumor cells of nasopharyngeal carcinoma in vivo. Lin Chung Er Bi Yan Hou Tou Jing Wai Ke Za Zhi. 2008;22:995-997.

84. Hadaschik BA, Zhang K, So AI, et al. Oncolytic vesicular stomatitis viruses as intravesical agents against non-muscle-invasive bladder cancer. Urologe. 2008;47:1145-1151.

85. Hadaschik BA, Zhang K, So AI, et al. Oncolytic vesicular stomatitis viruses are potent agents for intravesical treatment of high-risk bladder cancer. Cancer Res. 2008;68:4506-4510.

86. Letchworth GJ, Rodriguez LL, Del cbarrera J. Vesicular stomatitis Vet J. 1999;157:239-260.

87. Schnell MJ, Buonocore L, Whitt MA, Rose JK. The minimal conserved transcription stop-start signal promotes stable expression of a foreign gene in vesicular stomatitis virus. J Virol. 1996;70: 2318-2323.

88. Roberts A, Kretzschmar E, Perkins AS, et al. Vaccination with a recombinant vesicular stomatitis virus expressing an influenza virus hemagglutinin provides complete protection from influenza virus challenge. J Virol. 1998;72:4704-4711.

89. Schlereth B, Rose JK, Buonocore L, ter Meulen V, Niewiesk S. Successful vaccine-induced seroconversion by single-dose immunization in the presence of measles virus-specific maternal antibodies. $J$ Virol. 2000;74:4652-4657

90. Kahn JS, Schnell MJ, Buonocore L, Rose JK. Recombinant vesicular stomatitis virus expressing respiratory syncytial virus (RSV) glycoproteins: RSV fusion protein can mediate infection and cell fusion. Virology. 1999;254:81-91.

91. Chen NN, Reiss CS. Innate immunity in viral encephalitis: Role of C5. Viral Immunol. 2002;15:365-372.

92. Chesler DA, Reiss CS. The role of IFN-gamma in immune responses to viral infections of the central nervous system. Cytokine Growth Factor Rev. 2002;13:441-454.

93. Ireland DDC, Reiss CS. Gene expression contributing to recruitment of circulating cells in response to vesicular stomatitis virus infection of the CNS. Viral Immunol. 2006;19:536-545.

94. Ireland DD, Bang T, Komatsu T, Reiss CS. Delayed administration of interleukin-12 is efficacious in promoting recovery from lethal viral encephalitis. Viral Immunol. 1999;12:35-40.

95. Cua DJ, Sherlock J, Chen Y, et al. Interleukin-23 rather than interleukin12 is the critical cytokine for autoimmune inflammation of the brain. Nature. 2003;421:744-748.

96. Yuan X, Hu J, Belladonna ML, Black KL, Yu JS. Interleukin-23expressing bone marrow-derived neural stem-like cells exhibit antitumor activity against intracranial glioma. Cancer Res. 2006;66:2630-2638.

97. Munson AE, Phillips KE. Natural killer cells and immunotoxicology. Methods Mol Biol. 2000;121:359-365.

98. Min B, Foucras G, Meier-Schellersheim M, Paul WE. Spontaneous proliferation, a response of naive CD4 $\mathrm{T}$ cells determined by the diversity of the memory cell repertoire. Proc Natl Acad Sci U S A. 2004;101:3874-3879.

99. Roberts A, Buonocore L, Price R, Forman J, Rose JK. Attenuated vesicular stomatitis viruses as vaccine vectors. J Virol. 1999;73: 3723-3732. 
100. Fernandez M, Porosnicu M, Markovic D, Barber GN. Genetically engineered vesicular stomatitis virus in gene therapy: application for treatment of malignant disease. J Virol. 2002;76:895-904.

101. Obuchi M, Fernandez M, Barber GN. Development of recombinant vesicular stomatitis viruses that exploit defects in host defense to augment specific oncolytic activity. $J$ Virol. 2003;77:8843-8856.
102. Frucht DM, Fukao T, Bogdan C, Schindler H, O’Shea JJ, Koyasu S. IFN-gamma production by antigen-presenting cells: mechanisms emerge. Trends Immunol. 2001;22:556-560.

\section{Publish your work in this journal}

The International Journal of Interferon, Cytokine and Mediator Research is an international, peer-reviewed, open-access, online journal. The focus of the journal is to publish original research, reports, editorials, reviews and commentaries on all aspects of interferon, cytokine and mediators of inflammation from laboratory science to therapeutic indications and clinical studies. The manuscript management system is completely online and includes a very quick and fair peer-review system, which is all easy to use. Visit http://www.dovepress.com/testimonials.php to read real quotes from published authors.

Submit your manuscript here: http://www.dovepress.com/international-journal-of-interferon-cytokine-and-mediator-research-journal 